\title{
Investigation of dissolved salts on heat transfer for aluminum alloy 2024 during spray quenching
}

\author{
Ruichao Guo, Jianjun $\mathrm{Wu}^{*}$, He Fan, Xuepeng Zhan, Yu Hui \\ School of Mechanical Engineering, Northwestern Polytechnical University, Xi'an 710072, PR China
}

A R T I C L E I N F O

Keywords:

Spray quenching

Dissolved salts

Aluminum alloy

Heat transfer

\section{A B S T R A C T}

An experiment was performed to investigate the influence of four dissolved salts $\left(\mathrm{NaCl}, \mathrm{CaCl}_{2}, \mathrm{Na}_{2} \mathrm{SO}_{4}\right.$ and $\left.\mathrm{MgSO}_{4}\right)$ on heat transfer. Concentration of all salts varied from $0.01 \mathrm{M}$ to $0.4 \mathrm{M}$. And deionized water (DI water) was used as the solvent. The aluminum alloy 2024 thin sheets were heated to $495^{\circ} \mathrm{C}$ and quenched by two spray nozzles with a constant range of volumetric flux. Time-temperature curves were smoothed by B-spline approximation with a smoothing parameter of $10^{-4}$. The results indicate that only $\mathrm{MgSO}_{4}$ solution increases both nucleate boiling and transition boiling heat flux. Solution of $\mathrm{CaCl}_{2}$ has the greatest influence on nucleate boiling heat transfer, followed by $\mathrm{Na}_{2} \mathrm{SO}_{4}$ compared with the minimum influence of $\mathrm{NaCl}$. These effects are attributed to the surface tension gradient, transition concentration and vapor pressure for different salts. The largest heat flux enhancement is observed at concentration of $0.2 \mathrm{M}$ for solutions of $\mathrm{NaCl}, \mathrm{CaCl}_{2}$ and $\mathrm{MgSO}_{4}$ in contrast to $0.06 \mathrm{M}$ for $\mathrm{Na}_{2} \mathrm{SO}_{4}$.

\section{Introduction}

With good forming ability and fatigue resistance, especially in thin sheets forms, aluminum alloy 2024 sheet products are often used in commercial and military aircraft for fuselage skins and wing skins and structural areas where stiffness and lightweight are required [1]. To satisfy required mechanical properties of structures, thin sheets are usually quenched after heat treatment by various technologies, e.g. water or oil quenching, spray quenching or air-water mixture quenching [2].

Spray quenching, due to its high removal of heat flux, has been extensively used in thermal management of electronic devices, rapid cooling of hot surface and aluminum industry [3, 4]. However, because of complicated spray hydrodynamics, various material surface conditions and other parameters which are not easily varied, the heat transfer mechanisms during spray quenching are difficult to be understand.

In spray quenching technology, the main parameters for determination of heat flux are volumetric flux $Q^{\prime \prime}$, Sauter mean diameter $d_{32}$ and mean droplet velocity $U_{\mathrm{m}}[5,6,7]$. Mudawar and Deiters [8] investigated heat transfer coefficient below the film boiling regime. The results showed that heat transfer coefficient followed Gaussian distribution with the distribution of volumetric flux. But heat transfer coefficient declined slightly with the mean droplet velocity. Al-Ahmadi and Yao [9] indicated that vo-

\footnotetext{
* Corresponding author at: Northwestern Polytechnical University, 127 West Youyi Road, Xi'an Shaanxi, 710072, PR China Tel: +8602988493101

E-mail address: wujj@nwpu.edu.cn (J.J.Wu)
} 
lumetric flux was the most important parameter, which had the strongest effects on the determination of Leidenfrost point and critical heat flux. Rybicki and Mudawar [10] examined sprays orientation on quenching performance using FC-72, FC-87 and water, and they found that volumetric flux and Sauter mean diameter were key parameters that could influence spray quenching performance. Wendelstorf et al. [11] also indicated volumetric flux was the most important parameter, and they found that heat transfer coefficient had a strong effect on surface temperature below a specific surface temperature. However, Chen et al. [12] had a different view. The effects of mean droplet velocity, Sauter mean diameter and volumetric flux were experimentally investigated. They found that mean droplet velocity had the most dominant influence on heat transfer coefficient and critical heat flux.

Recent research has found that dissolved salts can improve the effectiveness of spray quenching. Cui et al. [13] studied the effects of dissolving gas (carbon dioxide, $\mathrm{CO}_{2}$ ) and salts (sodium carbonate, $\mathrm{Na}_{2} \mathrm{CO}_{3}$ and sodium bicarbonate, $\mathrm{NaHCO}_{3}$ ) on heat transfer performance during spray quenching. The results showed that both $\mathrm{Na}_{2} \mathrm{CO}_{3}$ and $\mathrm{NaHCO}_{3}$ decreased droplet evaporation rates due to lower surface temperature. However, dissolved $\mathrm{CO}_{2}$ improved evaporation rates slightly. They also found that $\mathrm{NaHCO}_{3}$ reduced droplet lifetime more than $\mathrm{Na}_{2} \mathrm{CO}_{3}$. When surface temperature was higher than Leidenfrost temperature, the dissolved salts increased heat transfer. In their subsequent studies [14, 15], the influences of sodium chloride $(\mathrm{NaCl})$, sodium sulfate $\left(\mathrm{Na}_{2} \mathrm{SO}_{4}\right)$ and magnesium sulfate $\left(\mathrm{MgSO}_{4}\right)$ were comprehensively studied. The results showed that dissolved $\mathrm{MgSO}_{4}$ increased both nucleate and transition boiling heat transfer compared with the dissolved $\mathrm{NaCl}$ and $\mathrm{Na}_{2} \mathrm{SO}_{4}$ which increased nucleate boiling heat transfer, but had little effect on transition boiling heat transfer. Huang and Carey [16] experimentally investigated the influence of dissolved salts $(\mathrm{NaCl}$ and potassium chloride $(\mathrm{KCl})$ ) on Leidenfrost evaporation. The results were demonstrated that the dissolved salts increased the Leidenfrost temperature. They indicated that the suppression of bubble coalescence was the mechanism affecting the Leidenfrost transition. Abdalrahman et al. [17] intensively studied the effects of single dissolved salt $\left(\mathrm{MgSO}_{4}\right)$ and real solutions used in aluminum industry. The electrical conductivity was introduced as means of estimating the salinity of spray water. It was found that salts mixtures had stronger effects on heat transfer compared with the single dissolved salt. Alam [18] studied different salts $(\mathrm{NaCl}$, $\mathrm{Na}_{2} \mathrm{SO}_{4}, \mathrm{NaHCO}_{3}, \mathrm{MgSO}_{4}$ and $\mathrm{Na}_{2} \mathrm{CO}_{3}$ ), the results indicated that deposition of salts at higher temperature may degrade the surface roughness and promote nucleate boiling heat transfer. The result was different with Cui's finding [15], which showed that the deposited $\mathrm{MgSO}_{4}$ particles increased the surface roughness.

According to the above references, different dissolved salts can have large differences. These differences may be attributed to the valences of salt ions or concentration of salts, even the heated temperature used in the experiment. Such salt changes can have effects on thermo-physical properties. The objective of the present work is to generate useful information for spray quenching of aluminum at high volumetric flux. Therefore, four kinds of ionic valences combination $(+1$ and $-1,+1$ and $-2,+2$ and -1 , +2 and -2$)$ are selected. And four salts $\left(\mathrm{NaCl}, \mathrm{CaCl}_{2}, \mathrm{Na}_{2} \mathrm{SO}_{4}\right.$ and $\left.\mathrm{MgSO}_{4}\right)$, which could inhibit bubble coalescence [19], are used. An apparatus is employed to provide a constant volumetric flux of approximately $0.023 \mathrm{~m}^{3} /\left(\mathrm{m}^{2} \mathrm{~s}\right)$. Concentration of each salt varies from $0.01 \mathrm{M}$ to $0.4 \mathrm{M}$, and deionized water is used as the solvent. Influences of four salt solutions on heat transfer are experimentally studied. 


\section{Experimental methods}

\subsection{Experimental setup and specimens}

Fig. 1a shows a schematic diagram of the water spray quenching system which is a modified version based on the apparatus of Guo et al. [20]. The main components of the system have the following sections: a water tank, a water spray quenching system and a data acquisition system. Spray water is pumped out of the water tank to quench specimens and water temperature used in this experiment is approximately $15^{\circ} \mathrm{C}$. Nozzle pressure is read by a pressure gauge and it can be regulated by a pressure regulator which consists of a pressure sensor, an inverter and a motor. This pressure controller holds the nozzle pressure within $\pm 5 \mathrm{kPa}$. Two commercial full-cone spray nozzles (Spraying Systems, Co., Ltd.), which are symmetrical on opposite sides of the quenching tank axis, are used in this study. Locations of spray nozzles are shown in Fig. 1b. It should be noted that all the connecting lines are made of 316 stainless steel to minimize corrosion.

The spray angle is $45^{\circ}$ and nozzle orifice diameter is $2.4 \mathrm{~mm}$. Nozzle distance of $80 \mathrm{~mm}$ is used to ensure that the heated area of specimens is contacted with sprays. The uncertainty of nozzle distance is $\pm 0.5 \mathrm{~mm}$ and the accuracy of symmetry of two nozzles is $\pm 1^{\circ} \quad$ (see Fig. 2). Measured temperature data are collected and recorded by a data acquisition system which includes a data acquisition module (OM-DAQ-USB-2401, USA) and a personal computer.

Present procedure is to use thermocouple in the middle of two sheets to obtain the surface temperature. A $0.013 \mathrm{~mm}$ diameter CHROMEGA ${ }^{\circledR}-$ ALOMEGA $^{\circledR}$ thermocouple (CO2-K, OMEGA, USA) is installed at the center of two sheets. The CO2-K thermocouples have an uncertainty of $\pm 0.75 \%$ full scale according to manufacture. High temperature air set cement (OMEGABOND $\left.{ }^{\circledR} 400\right)$ is applied to ensure good contact between surface of sheets and thermocouples. The test sheets, which are $60 \mathrm{~mm} \times$ $60 \mathrm{~mm}$ in square and $0.508 \mathrm{~mm}$ in thickness, are used in the experiments. The surface roughness is approximately $0.8 \mu \mathrm{m}$ for all sheets, ensuring cavity spacing relatively uniform. The material of test sheets is aluminum alloy 2024 and typical chemistries of alloy 2024 are listed in Table 1 .The density of aluminum alloy 2024 is assumed to be constant $\left(2780 \mathrm{~kg} / \mathrm{m}^{3}\right)$. The thermal conductivity and specific heat capacity of aluminum alloy 2024 obey the following equations [21], respectively. The conductivity and heat capacity have an uncertainty of approximately $5 \%$.

$$
\begin{array}{ll}
\lambda_{P}=167.7+0.108 \times T\left({ }^{\circ} \mathrm{C}\right) & 0^{\circ} \mathrm{C} \leq T \leq 500^{\circ} \mathrm{C} \quad \text { unit }: W /\left(m \cdot{ }^{\circ} \mathrm{C}\right), \\
c_{P}=856.7+0.891 \times T\left({ }^{\circ} \mathrm{C}\right) & 0^{\circ} \mathrm{C} \leq T \leq 500^{\circ} \mathrm{C} \quad \text { unit: } \mathrm{J} /\left(\mathrm{kg} \cdot{ }^{\circ} \mathrm{C}\right) .
\end{array}
$$




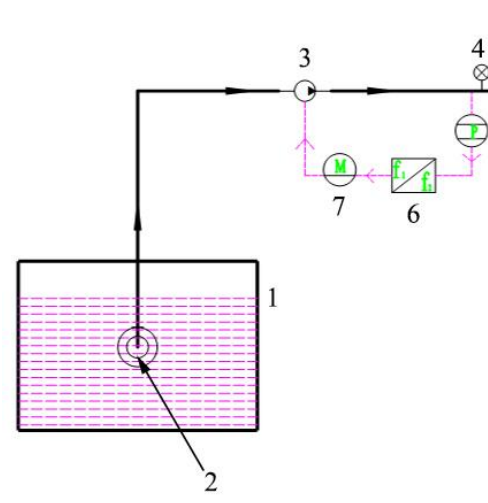

(a)

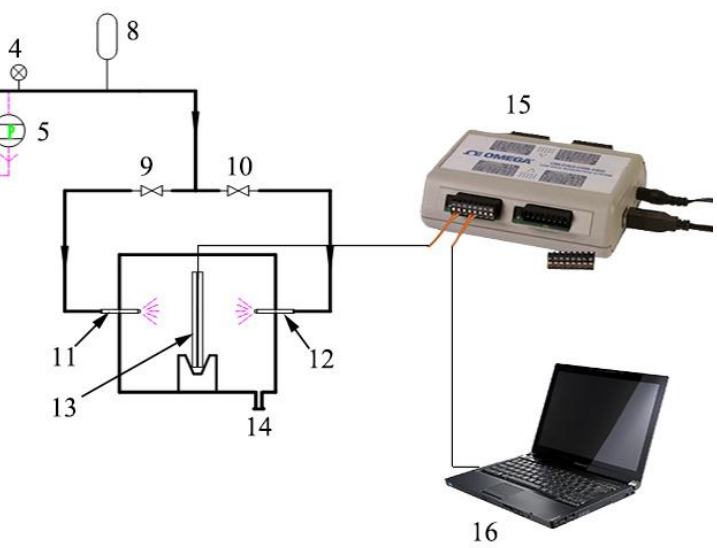

1-Water tank, 2-Bottom valve, 3-Pump, 4-Pressure gauge, 5-Pressure sensor, 6-Inverter, 7-Motor, 8-Pressure tank, 9-Bypass valve 1, 10-Bypass valve 2, 11-Nozzle 1, 12-Nozzle 2, 13-Specimens, 14-Water exit, 15-Data acquisition module, 16-Computer

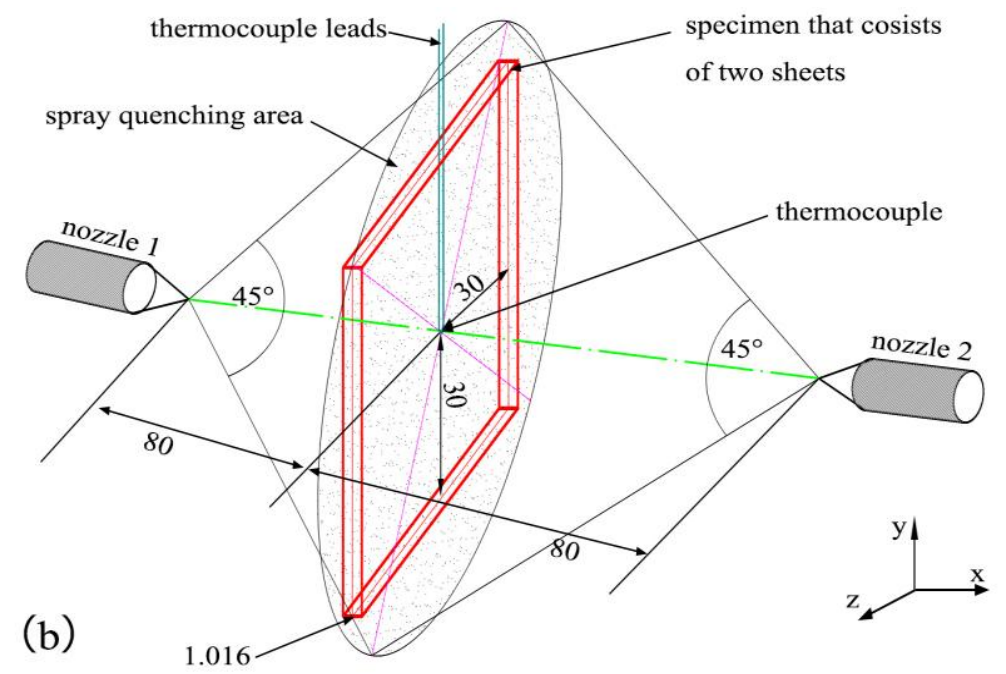

Fig. 1. Schematic diagram of (a) apparatus for spray quenching and (b) nozzles and thermocouple locations (unit: $\mathrm{mm})$.

\section{Table 1}

Aluminum alloy 2024 limits (wt \%).

\begin{tabular}{cccccccccccc}
\hline Chemistry & $\mathrm{Si}$ & $\mathrm{Fe}$ & $\mathrm{Cu}$ & $\mathrm{Mn}$ & $\mathrm{Mg}$ & $\mathrm{Cr}$ & $\mathrm{Zn}$ & $\mathrm{Ti}$ & $\mathrm{V}$ & $\mathrm{Zr}$ & $\mathrm{Al}$ \\
\hline Min & 0.00 & 0.00 & 3.80 & 0.30 & 1.20 & 0.00 & 0.00 & 0.00 & 0.00 & 0.00 & \\
$\operatorname{Max}$ & 0.50 & 0.50 & 4.90 & 0.90 & 1.80 & 0.10 & 0.25 & 0.15 & 0.05 & 0.05 & Balance \\
\hline
\end{tabular}

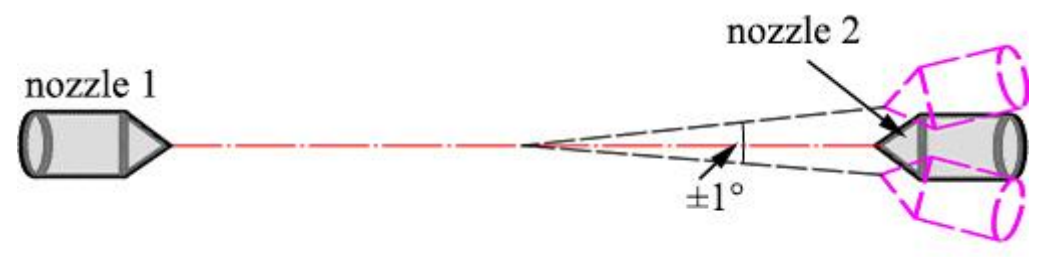

Fig. 2. Schematic diagram of two nozzles' symmetry. 


\subsection{Solution preparation and heat transfer process}

To minimize the effects of other ions, deionized water (DI water) is selected as the solvent of salt solutes. All powdered salts are of analytical reagent quality. After the required quality of salts is weighed by a precision balance which has an accuracy of $\pm 0.01 \mathrm{~g}$, all salt solutes are dissolved in deionized water. And then solutions are stirred to ensure complete mixing. Each solution is prepared before experiment.

Specimens are heated to $495^{\circ} \mathrm{C}$ by resistive heaters and retained for 30 minutes in furnace. The precision of furnace is $\pm 1^{\circ} \mathrm{C}$ based on digital temperature controller. And then specimens are quickly transferred to the quenching position. When nozzle pressure reaches the set value, two bypass valves are simultaneously turned on, ensuring that surfaces of two specimens are symmetrically impinged. A constant nozzle pressure of $300 \mathrm{kPa}$ is applied in this experiment. After the specimens are transferred to the position, temperatures are recorded instantly by the data acquisition system with a high rate of 100 Hz. This data acquisition system has an error of approximately $\pm 1.2^{\circ} \mathrm{C}$ for K-type thermocouples. The uncertainty of heat flux is calculated by a root summary square method of partial derivatives based on Moffat's theory [22]. Main errors from the spray quenching apparatus and the calculated values are listed in Table 2.

\section{Table 2}

Summary of errors.

\begin{tabular}{cc}
\hline Sources of error & Error \\
\hline Nozzle pressure & $\pm 5 \mathrm{kPa}$ \\
Heated temperature of specimens & $\pm 1^{\circ} \mathrm{C}$ \\
CO2-K thermocouples & $\pm 0.75 \%$ \\
Quantity of salts & $\pm 0.01 \mathrm{~g}$ \\
Temperature measurement & $\pm 1.2^{\circ} \mathrm{C}$ \\
Nozzle distance & $\pm 0.5 \mathrm{~mm}$ \\
Symmetry of two nozzles & $\pm 1^{\circ}$ \\
The conductivity and specific heat capacity & $\pm 5 \%$ \\
Heat flux & $\pm 3.02 \%$ \\
\hline
\end{tabular}

As indicated earlier (Section 1), the volumetric flux $Q$ " and Sauter mean diameter $d_{32}$ are the key parameters that have an influence on the spray quenching performance. Cui et al. [15] indicates that the change of concentration has a little effect on Sauter mean diameter. Thus, the value of Sauter mean diameter for all solutions can be estimated by the deionized water, following the equation [23]

$$
d_{32}=3.67 d_{0}\left[\frac{2 \rho_{g}^{0.5} P_{N} d_{0}^{1.5}}{\sigma^{0.5} \mu_{f}}\right]^{-0.259},
$$

where $P_{N}$ is the nozzle pressure $(P a), d_{0}$ is the orifice diameter of nozzles $(m), \rho_{g}$ is vapor densi$\operatorname{ty}\left(\mathrm{kg} / \mathrm{m}^{3}\right), \sigma$ is the surface tension $(N / m)$ and $\mu_{f}$ is water viscosity $\left(N \cdot s / m^{2}\right)$. The Sauter mean diameter $d_{32}$ is approximately $0.319 \mathrm{~mm}$ when the relevant properties of DI water in Ref. [24] are used.

Mudawar and Estes [25] gives the determination of volumetric flux for full-cone spray nozzle. It is defined as a function of flow rate $Q$, nozzle distance $D_{N}$, spray angle $\theta$ and radial location $r$ (as is shown in Fig. 3) 


$$
Q^{\prime \prime}=\left(\frac{Q}{2 \pi D_{N}^{2}(1-\cos (\theta / 2))}\right) \times\left(\frac{1}{\left[1+\left(r / D_{N}\right)^{2}\right]^{3 / 2}}\right)
$$

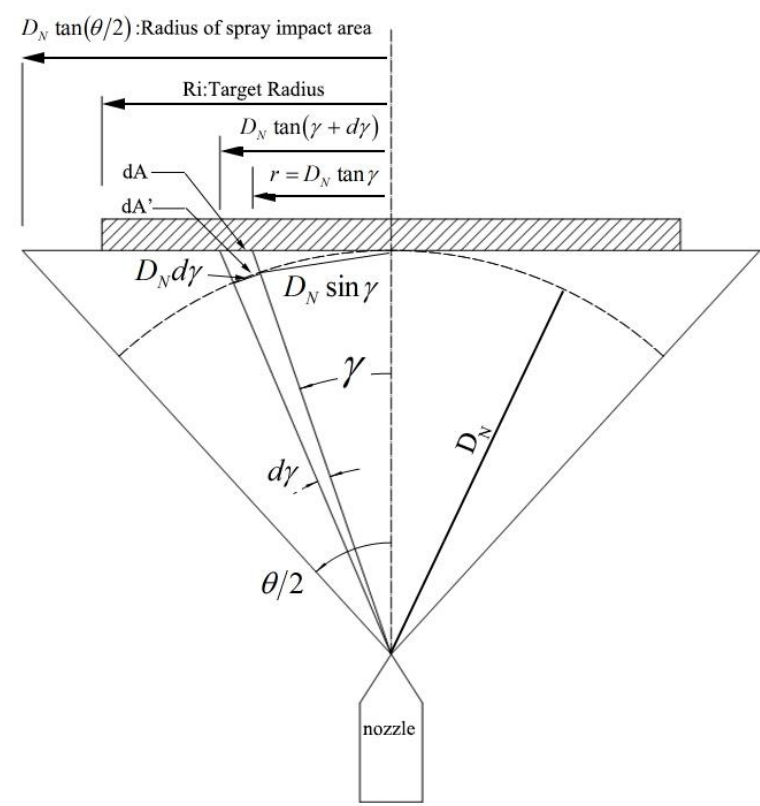

Fig. 3. Schematic diagram of volumetric flux distribution (Mudawar and Estes [25]).

The data from Table 3 are used to determine volumetric flux. Characteristics of spray quenching are listed in Table 3.

\section{Table 3}

Experimental conditions and characterization of sprays used in this work.

\begin{tabular}{cc}
\hline Characteristic & Value \\
\hline Spray angle $\theta\left(^{\circ}\right)$ & 45 \\
Nozzle orifice diameter $d_{0}(\mathrm{~mm})$ & 2.4 \\
Nozzle distance $D_{N}(\mathrm{~mm})$ & 80 \\
Water temperature $\left.T_{w}{ }^{\circ} \mathrm{C}\right)$ & 15 \\
Nozzle pressure $P_{N}(\mathrm{kPa})$ & 300 \\
Flow rate $Q(\mathrm{~L} / \mathrm{min})$ & 4.8 \\
Sauter mean diameter $d_{32} \times 10^{3}(\mathrm{~mm})$ & 319 \\
Volumetric flux $Q "\left(m^{3} /\left(m^{2} s\right)\right)$ & $0.02061-0.02614$ \\
\hline
\end{tabular}

\subsection{Data processing and inverse determination of heat flux}

It is difficult to measure surface temperature directly. Since specimen can be approximated as one-dimensional along thickness direction, the surface temperature and surface heat flux can be calculated when the temperature and heat flux at center of specimen are known. And the thermo-physical properties of specimens also should be given. Such a problem is an inverse heat conduction problem (IHCP).

The one-dimensional Fourier heat conduction equation is as follows 


$$
\frac{\partial}{\partial x}\left(\lambda_{P} \frac{\partial T}{\partial x}\right)=\rho_{P} c_{P} \frac{\partial T}{\partial t},
$$

where $\lambda_{P}, c_{P}, \rho_{P}, t, T(x, t)$ are the thermal conductivity of sheet in Eq. (1), specific heat capacity in Eq. (2), density of sheet, time and objective temperature, respectively.

For symmetry reason, the heat flux at $x=0$ is

$$
-\left.\lambda_{P} \frac{\partial T}{\partial x}\right|_{x=0}=0
$$

where $x$ is the distance from the center of two sheets to target location.

The temperature of specimens at any time can be set uniform because the Biot number $h \delta / \lambda_{P}$ is approximately $0.02<0.1$. Therefore, surface heat flux can be calculated by solving Eqs. (5) and (6)

$$
q(\delta, t)=-\rho_{P} c_{P} \frac{d y}{d t} \delta,
$$

where $h, \delta$ and $y(t)$ are heat transfer coefficient of specimens, thickness of sheets and the measured temperature history, respectively. The Eq. (7) is an exceptional case for the general solution of IHCP given by Burggraf [26] when Biot number is very small.

Because of the high frequencies of data acquisition module, it is clear that the discrete data contain true random noise which can cause convergence problem for inverse heat flux calculation. As pointed out by Vorster et al. [27], temporal data smoothing is a reasonable approximation if the discrete data can be represented by a continuous, smooth and differentiable function. However, classical smoothing splines suffer from the defect that a change in a single data point may require the recalculation of the entire spline function.

A uniform B-spline curve of degree 3 is used to overcome the difficulty and smooth the discrete temperature data $\left(\tau_{i}, T_{i}\right) i=1, \ldots, n$. This method has also been used in our earlier works and proved effective [20,28]. The measured temperature $y(t)$ in the interval $\left(t_{1}, t_{m}\right)$ is smoothed as

$$
y(t)=\mathbf{U} \psi \text {. }
$$

With the objective function [29]

$$
\operatorname{Min} J=\zeta \int_{t_{1}}^{t_{m}}\left(y^{(2)}(t)\right)^{2} d t+\sum_{i=1}^{n}\left(y\left(\tau_{i}\right)-T_{i}\right)^{2},
$$

where

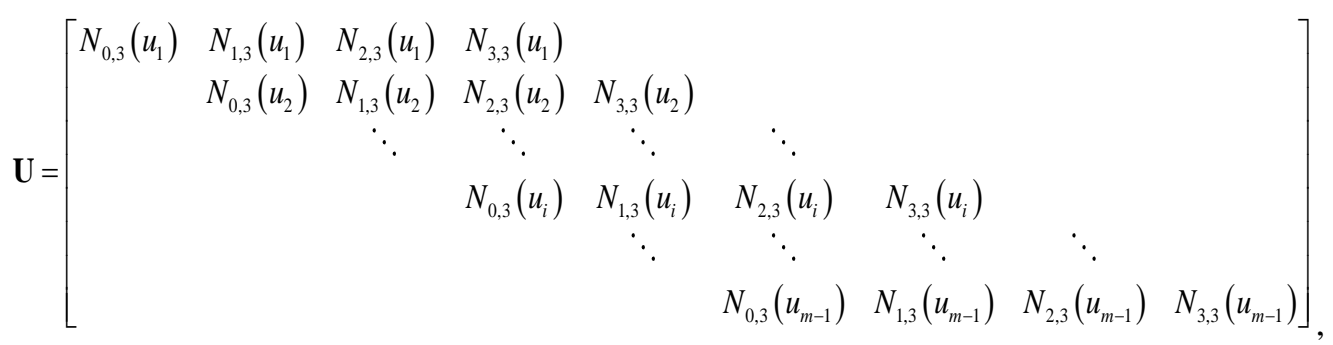

and $\boldsymbol{\psi}=\left(\psi_{-2}, \psi_{-1}, \psi_{0}, \psi_{1}, \ldots, \psi_{m-1}\right) \in \mathbf{R}^{m+2}$ is the control point vector. The elements $N_{j, 3} j=1,2,3$ in Eq. (10) are the basis functions of normalized uniform B-spline, and $\zeta$ is the smoothing parameter in Eq. (9).

Effects of smoothing parameters are displayed by a typical curve through six values $\left(10^{-1}, 10^{-2}\right.$, $10^{-3}, 10^{-4}, 10^{-5}$ and $10^{-6}$ ), as shown in Fig. 4. The discrete data are measured through the spray quenching of deionized water. 


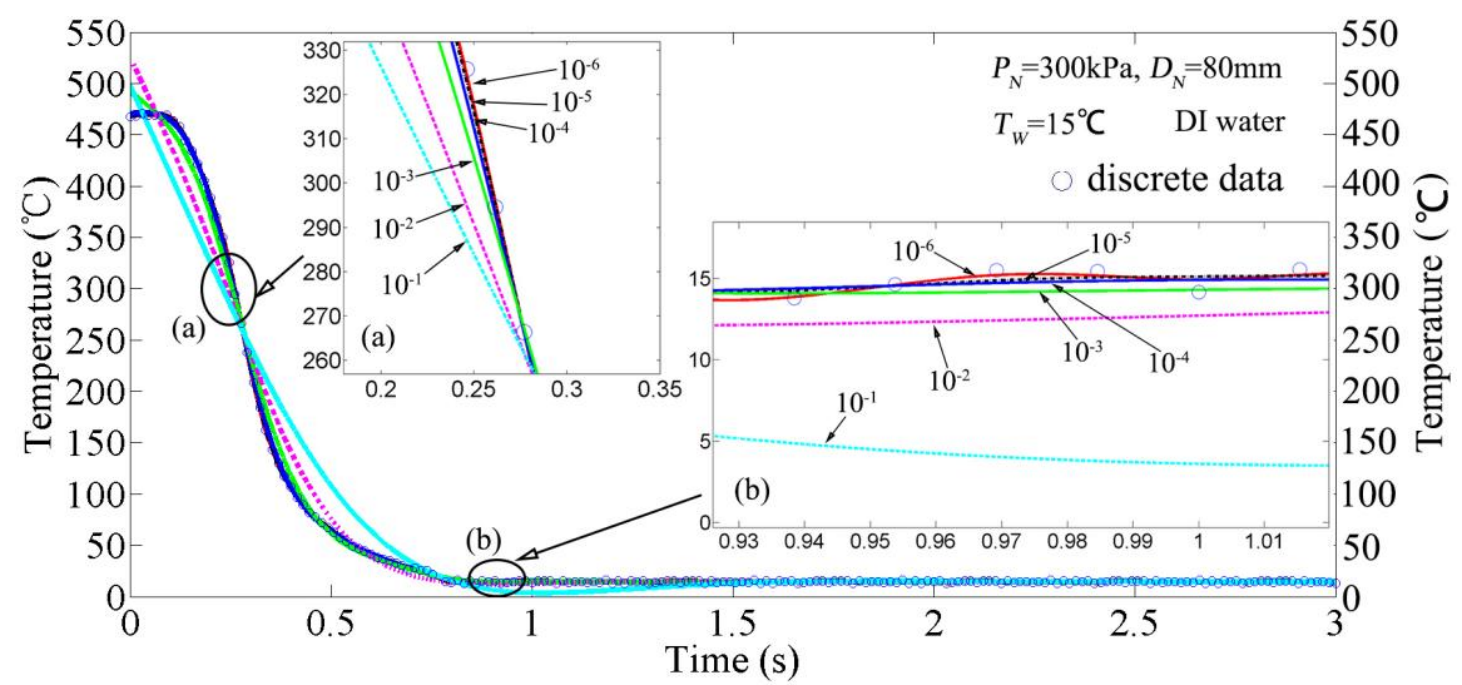

Fig. 4. The discrete data and smoothed curves obtained by B-spline approximation with different smoothing para-

meters.

From Fig. 4, it can be seen that the curves with smoothing parameters of $10^{-1}, 10^{-2}$ and $10^{-3}$ remove the true signal of discrete data. Also, it shows that other three curves can describe the variation trend of discrete data when the smoothing parameters are $10^{-4}, 10^{-5}$ and $10^{-6}$. However, there exists truly random noise at the smoothing parameter of $10^{-6}$ (see the drawing of partial enlargement of Fig. 4(b)). This phenomenon is due to high frequency of the input signal. When the smoothing parameters are $10^{-4}$ and $10^{-5}$, the two curves have the similar trends (see the drawing of partial enlargement of Fig. 4(a) and 4(b)). As pointed out by Taler [30], it produces noise in surface heat flux when the smoothing parameter is too small. Thereby, a smoothing parameter of $10^{-4}$ is chosen in this work.

The repeatability is very important, and a typical result (deionized water) with a smoothing parameter $\zeta=10^{-4}$ is displayed in Fig. 5 .

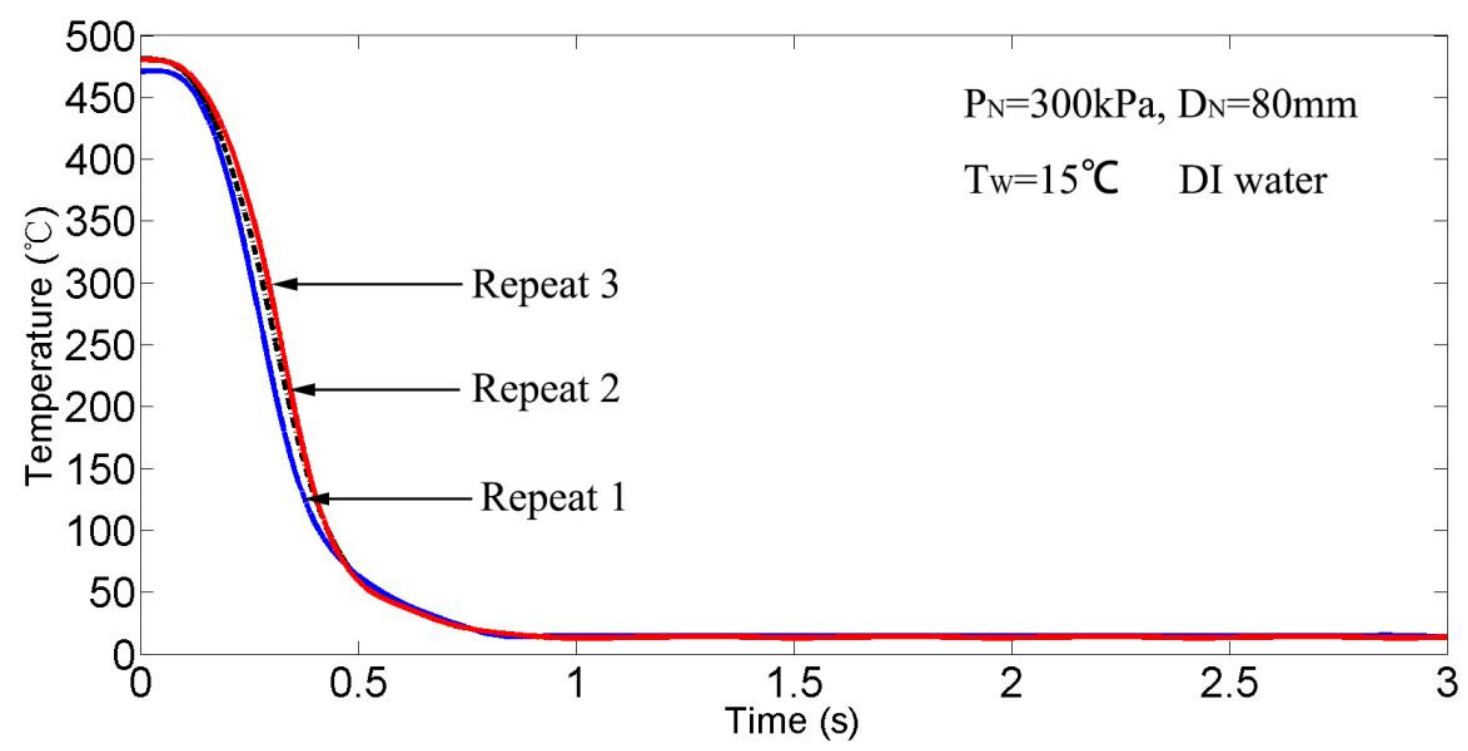

Fig. 5. A typical quenching profile repeated three times using deionized water.

From Fig. 5, we can see that the repeatability is considered good as a statistical fluctuation. The error is within $3 \%$ in the repeatability. Therefore, repetitions are done in every experimental group and any observed difference can be considered as the effect of dissolved salts on heat transfer rather than any change in volumetric flux or Sauter mean diameter, or even the experimental error. 


\section{Results and discussion}

\subsection{Surface temperature and heat flux profiles}

Fig. 6 shows a serious of typical spray quenching curves when $\mathrm{MgSO}_{4}$ is used as a solute. The quenching conditions for these curves are identical, but the concentration of dissolved salt is different. All the curves are smoothed by B-spline approximation to filter the true noise. It can be found that the initial temperatures of different curves are lower than the heated temperature $\left(495^{\circ} \mathrm{C}\right)$ because of the inconsistent transferred time. And there have minor changes of the temperature during the air cooling regime. When the sprays impinge onto the specimens, the temperatures have a remarkable reduction and the duration is very short. It takes approximately $0.5 \mathrm{~s}$ to decrease from $470^{\circ} \mathrm{C}$ to $100^{\circ} \mathrm{C}$ as opposed to approximately $0.3 \mathrm{~s}$ from $100^{\circ} \mathrm{C}$ to $15^{\circ} \mathrm{C}$. Comparing the five curves shows that it drops fastest for the surface temperature when the concentration of $\mathrm{MgSO}_{4}$ is $0.2 \mathrm{M}$, followed by $0.4 \mathrm{M}$. The relatively slowest curve is the DI water. The reason behind this phenomenon is the influence of dissolved salt on heat transfer and will be discussed in next section.

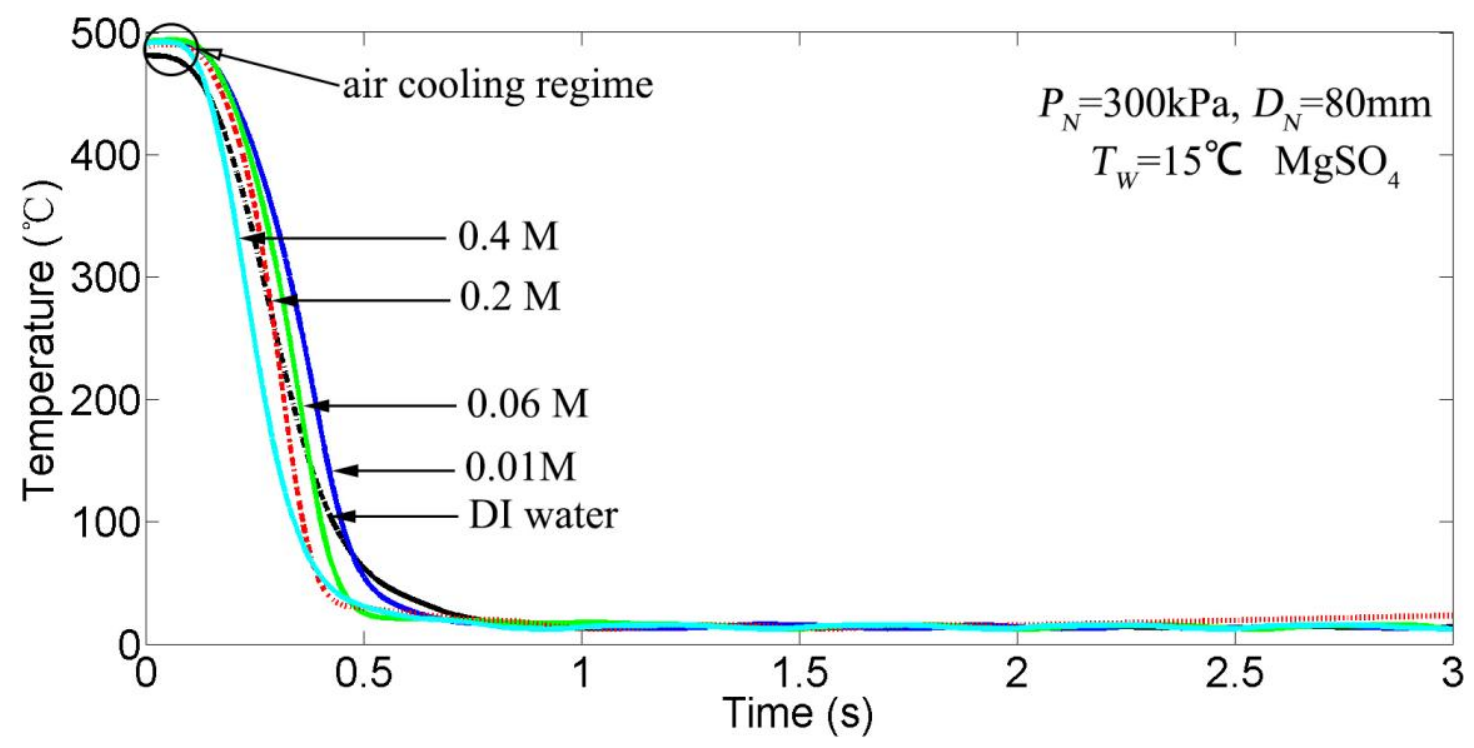

Fig. 6. Example of measured spray quenching curves when the $\mathrm{MgSO}_{4}$ is used as solute.

When the DI water is used, the variation of heat flux during spray quenching is shown in Fig. 7. It is generally believed that with the surface temperature decreasing, different conditions such as transition boiling, nucleate boiling and single phase heat transfer successive occur. In the transition boiling regime, the heat flux increases with the decreasing of surface temperature. It reaches the maximum value (critical heat flux, CHF) at the surface temperature of $293{ }^{\circ} \mathrm{C}$. CHF value is approximately $2.5 \mathrm{MW} / \mathrm{m}^{2}$ for the DI water. And this value is a little higher than that of the result of Al-Ahmadi and Yao [9], which finds that CHF value is approximately $2.25 \mathrm{MW} / \mathrm{m}^{2}$ at volumetric flux of $23 \mathrm{~kg} /\left(\mathrm{m}^{2} \mathrm{~s}\right)$ when the stainless steel is spray quenched. The phenomenon may be attributed to the higher thermal conductivity for alloy 2024 than that for stainless steel. The heat flux decreases with surface temperature further reduction in the nucleate boiling regime $\left(100^{\circ} \mathrm{C}<T_{s}<293^{\circ} \mathrm{C}\right)$. Finally, heat is transferred through natural convection when the surface temperature is less than $100^{\circ} \mathrm{C}$ in the single phase regime. 


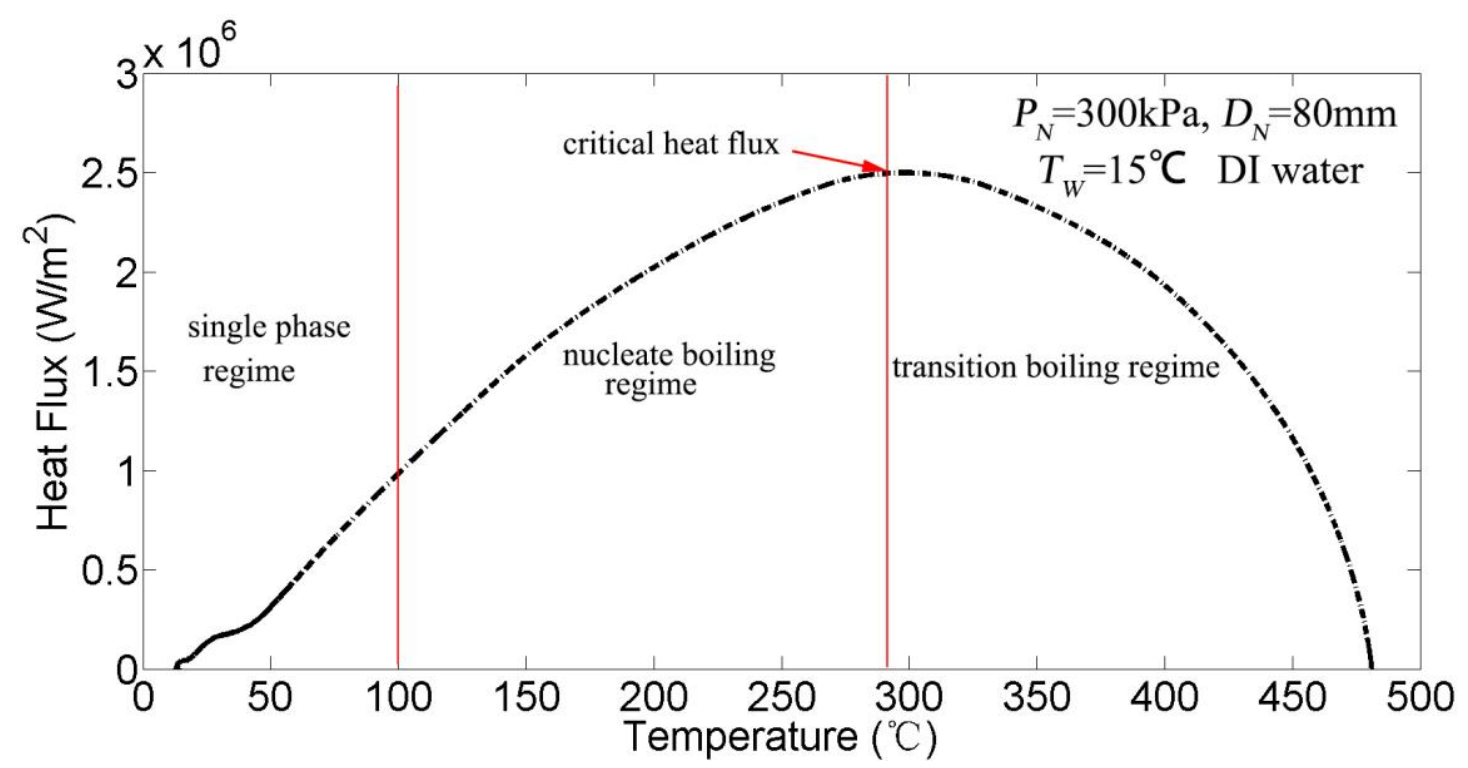

Fig. 7. The calculated heat flux during spray quenching when the DI water is used.

The result in Fig. 7 also reveals that film boiling regime and the minimum heat flux point are not observed. This feature is different from the result reported in Ref. [17], which shows that the minimum heat flux point occurs at surface temperature of approximately $250^{\circ} \mathrm{C}$ when the heated specimens $\left(560{ }^{\circ} \mathrm{C}\right)$ of aluminum alloy 6082 are spray quenched using DI water. Since there have similar thermo-physical properties between alloy 2024 and 6082, the results can be compared. The high volumetric flux used in this work may lead to the phenomenon. According to Al-Ahmadi and Yao [9] and Klinzing et al. [31], the minimum heat flux point temperature increases with the increasing volumetric flux. Therefore, it is hard to observe the minimum heat flux point at a higher volumetric flux. The phenomenon may also be caused by the low water temperature. Compared to the higher water temperature (approximately $18^{\circ} \mathrm{C}$ ) used in Ref. [17], it needs more heat to heat the water to the vaporization temperature for water temperature of $15^{\circ} \mathrm{C}$ in present work. Besides water temperature and volumetric flux, the comparatively low heated temperature may have little effect on the existence of film boiling regime. Cui et al. [15] also indicates that there exists film boiling regime when the heated copper cylinder $\left(240^{\circ} \mathrm{C}\right)$ is cooled by pure water at $95^{\circ} \mathrm{C}$.

\subsection{Effects of salts concentrations and types on nucleate and transition boiling}

Figs. 8a-d show the effects of different dissolved salts $\left(\mathrm{NaCl}, \mathrm{CaCl}_{2}, \mathrm{Na}_{2} \mathrm{SO}_{4}\right.$ and $\left.\mathrm{MgSO}_{4}\right)$ on heat flux. The concentration of dissolved salts varies from $0.01 \mathrm{M}$ to $0.4 \mathrm{M}$. It can be seen that there exists no film boiling and the minimum heat flux point for the four solutions at different concentrations. This agrees with the experimental result of Huang and Carey [16], which shows that the Leidenfrost temperature of dissolved salt is higher than that of DI water.

The four drawings also illustrate different features on both nucleate boiling regime and transition boiling regime. In nucleate boiling regime, it can be seen from Fig .8a that the heat transfer is enhanced when the concentration of $\mathrm{NaCl}$ solution varies from $0.01 \mathrm{M}$ to $0.4 \mathrm{M}$. The enhancement is greatest when the concentration of $\mathrm{NaCl}$ is $0.2 \mathrm{M}$, less for $0.4 \mathrm{M}$ and the least for $0.01 \mathrm{M}$. Similar trend is observed in Fig. 8d when the dissolved salt is $\mathrm{MgSO}_{4}$. And the general ranking of concentrations, which defines the descending order of effectiveness in nucleate boiling heat flux, is as follows: $0.2 M>0.06 M>0.01 M>0.4 M$. When a solution of $\mathrm{Na}_{2} \mathrm{SO}_{4}$ is used, the greatest enhancement is found at the concentration of $0.06 \mathrm{M}$ and a concentration of $0.01 \mathrm{M}$ comes the second. 
With the concentration of $\mathrm{Na}_{2} \mathrm{SO}_{4}$ further increasing, the enhancement of heat transfer is subsided at the concentration of $0.2 \mathrm{M}$, and even suppressed at the concentration of $0.4 \mathrm{M}$ (see Fig. 8c). For dissolved salt of $\mathrm{CaCl}_{2}$, the suppression of heat transfer is also observed at the concentration of $0.4 \mathrm{M}$. The largest increase of heat transfer is found when the concentration is $0.2 \mathrm{M}$, as shown in Fig. $8 \mathrm{~b}$. The enhancement factor during nucleate boiling is shown in Fig. 11a.
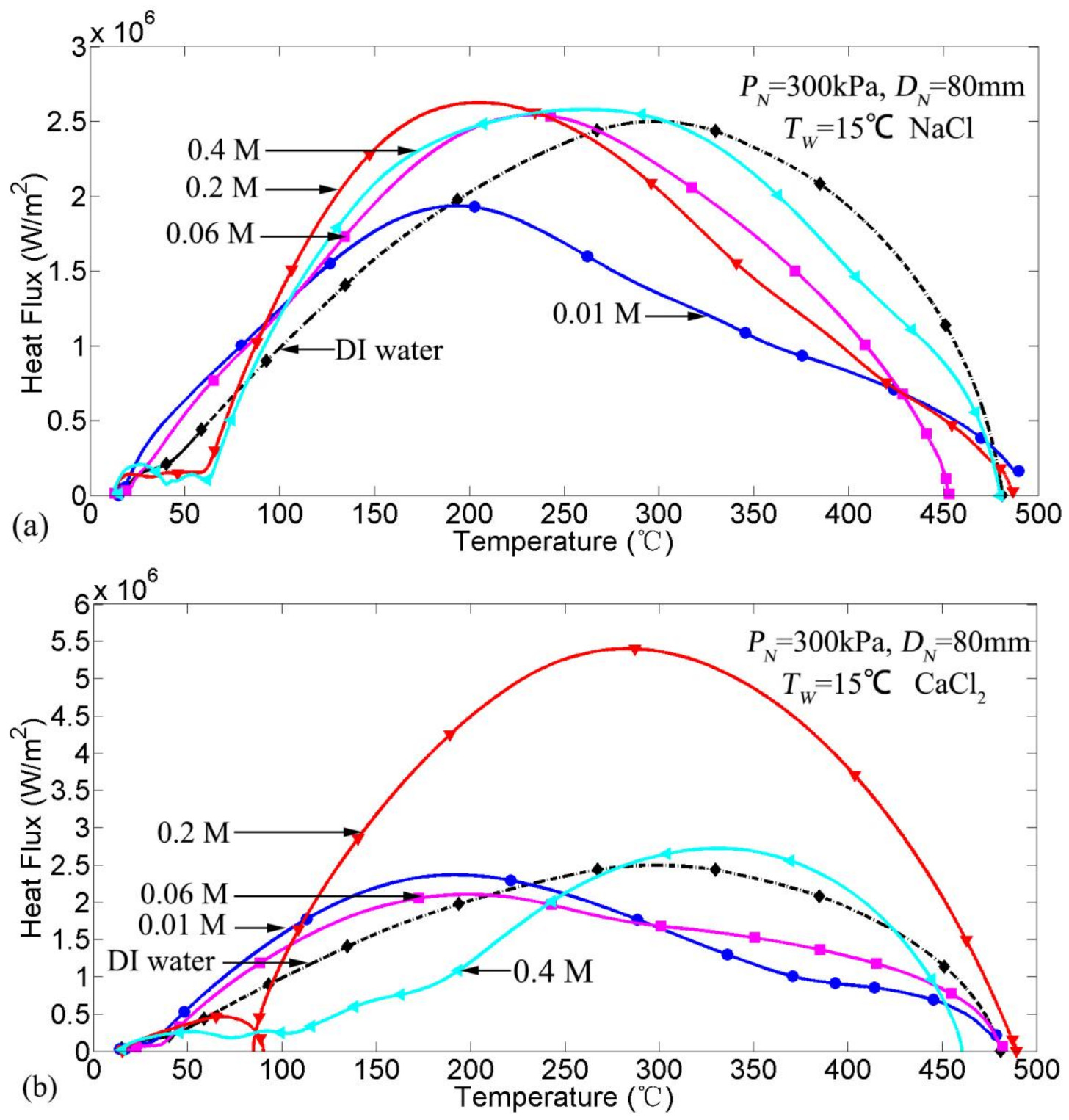

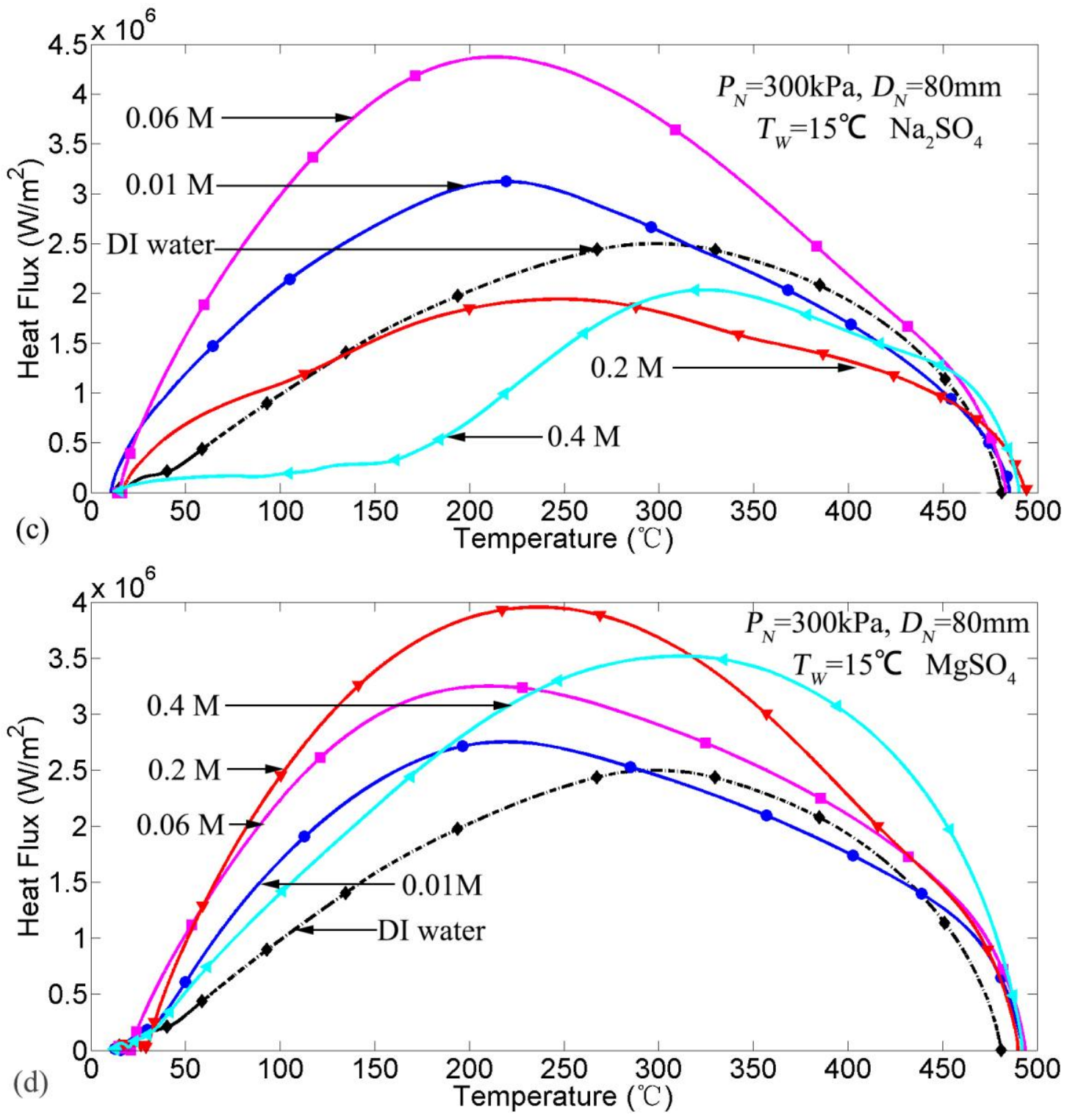

Fig. 8. The effect of dissolved salt on heat flux for aluminum 2024: (a) $\mathrm{NaCl}$; (b) $\mathrm{CaCl}_{2}$; (c) $\mathrm{Na}_{2} \mathrm{SO}_{4}$ and (d)

$$
\mathrm{MgSO}_{4} \text {. }
$$

It is known that a large number of bubbles are formed in the heated surface, promoting heat transfer in the nucleate boiling regime. Bubble coalescence can be prevented by dissolved salts, and the extent of suppression is dependent on salt type and concentration. According to Browne et al. [32], it is the surface tension gradient $(d \sigma / d c)$ due to non-uniform distribution of solute molecules that reduce bubble coalescence. Schematic inhibition mechanism is depicted in Fig. 9. Transition concentration $\left(C_{T}\right)$ defines the boundary, below which there is hardly any coalescence. The variations of surface tension gradient and transition concentration for salt solutions are displayed in Table 4. However, bubble departure diameter also increases with surface tension, which reduces the frequency of the bubbles. And it can be explained by the following equation

$$
D_{b} \propto \sqrt{\frac{\sigma}{g\left(\rho_{l}-\rho_{g}\right)}},
$$

where $\sigma$ is surface tension $(N / m), g$ is gravitational acceleration $\left(\mathrm{m} / \mathrm{s}^{2}\right), \rho_{l}$ is liquid density $\left(\mathrm{kg} / \mathrm{m}^{3}\right)$ and $\rho_{g}$ is vapor density $\left(\mathrm{kg} / \mathrm{m}^{3}\right)$. 
Increasing concentration of dissolved salt will reduce the vapor pressure, which is the most important of thermodynamic properties affecting liquids and vapors. The decreased vapor pressure results in the decreasing of droplet evaporation rate. Variations of vapor pressure with solutions concentration are shown in Fig. 10. The data are calculated based on the method of Ref. [34].

These combined effects lead to the results for different dissolved salts at different concentrations. Present results in Fig. 11a reveal that solution of $\mathrm{NaCl}$ has little effect on enhancement of heat transfer due to the minimum surface tension gradient and largest $C_{T}$ in the four salts. Solution of $\mathrm{MgSO}_{4}$ has the minimum $C_{T}$, smaller surface tension gradient and hardly any change of vapor pressure. Therefore, inhibition of coalescence occurs at low concentration. And further increasing of concentration leads to decline of heat transfer when the $\mathrm{MgSO}_{4}$ reaches the optimum salt concentration $(0.2 \mathrm{M})$. The Fig. 11a also shows that the decline of heat transfer is relatively small because there exists only bubble diameter increasing when the concentration of $\mathrm{MgSO}_{4}$ changes from $0.2 \mathrm{M}$ to $0.4 \mathrm{M}$. Dissolved salts of $\mathrm{Na}_{2} \mathrm{SO}_{4}$ and $\mathrm{CaCl}_{2}$ have similar $C_{T}$ (approximately $0.06 \mathrm{M}$ ). However, the surface tension gradient and descended vapor pressure of $\mathrm{CaCl}_{2}$ are higher than that of $\mathrm{Na}_{2} \mathrm{SO}_{4}$. These produce the difference in two curves. For a solution of $\mathrm{Na}_{2} \mathrm{SO}_{4}$, the heat transfer increases until reaching the concentration of $0.06 \mathrm{M}$. When the concentration exceeding $0.06 \mathrm{M}$, the influences of decreased vapor pressure and declined frequency of the bubbles on heat transfer are greater than the effect of inhibition of coalescence. So the heat transfer decreases with an increase in concentration. When dissolved salt of $\mathrm{CaCl}_{2}$ is used, it has the largest enhancement (at the concentration of $0.2 \mathrm{M}$ ) and fastest drop (at the concentration of $0.4 \mathrm{M}$ ) because the surface tension gradient and reduced vapor pressure are the highest in the four dissolved salts.

Table 4

Surface tension gradient and transition concentration for salt solutions [33].

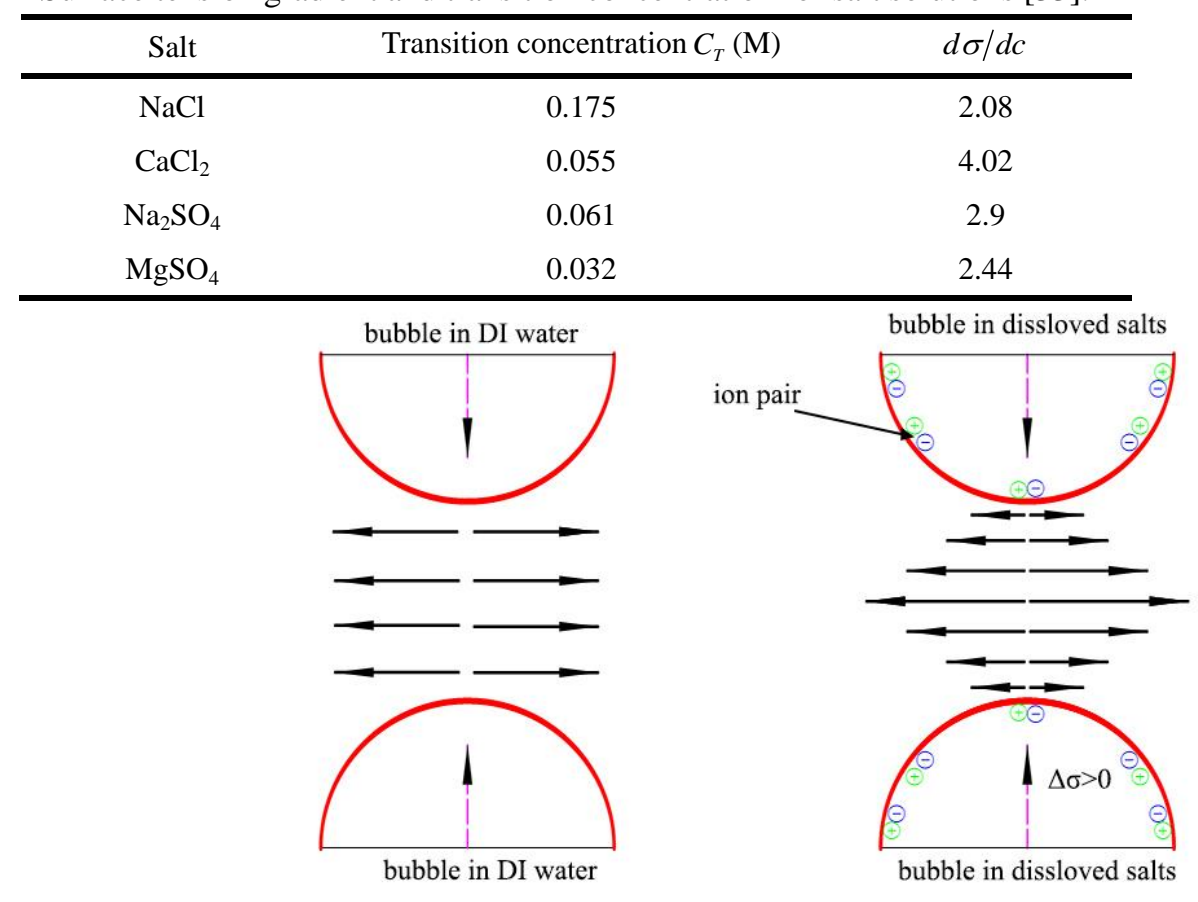

Fig. 9. Schematic inhibition mechanism of bubble coalescence [32]. 


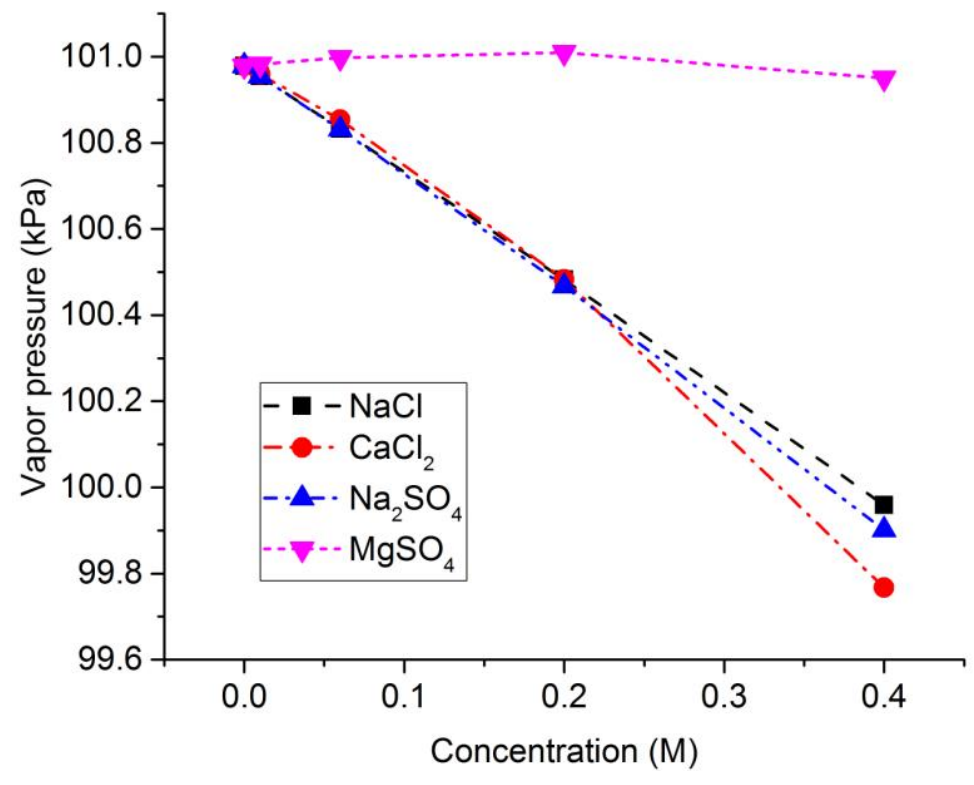

Fig. 10. Variations of vapor pressure with concentration at $373 \mathrm{~K}$.
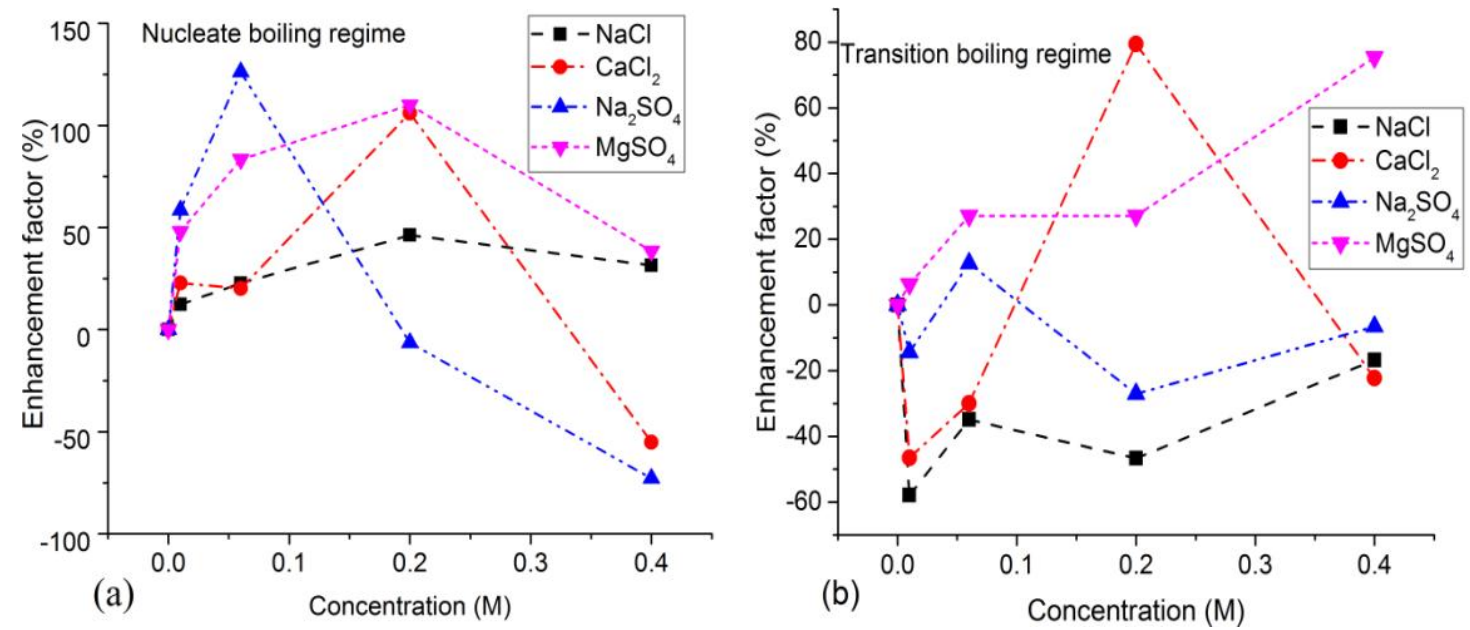

Fig. 11. The effect of salts concentration on heat transfer in (a) nucleate boiling and (b) transition boiling.

During transition boiling regime, nucleate boiling and the intermittent vapor film that can prevent liquid contact with heated surface, oscillate very rapidly. The results in transition boiling may be occurred by the following mechanisms. ( $i$ ) Increasing concentration of solutions, which can improve surface tension and liquid density, will decrease thickness of intermittent vapor film according to Biance et al. [35]

$$
e=\left(\frac{3 \lambda_{\mathrm{g}} \Delta T \mu_{\mathrm{g}}}{4 h_{f g} \rho_{l} \rho_{g} g a}\right)^{0.25} R^{0.5}
$$

where $\lambda_{g}, h_{f g}, R, \mu_{g}, a, \Delta T$ are thermal conductivity of vapor $\left(W /\left(m \cdot{ }^{\circ} \mathrm{C}\right)\right)$, latent heat of evaporation $(\mathrm{J} / \mathrm{kg})$, droplet radius $(\mathrm{m})$, vapor viscosity $\left(N \cdot s / \mathrm{m}^{2}\right)$, capillary length $(\mathrm{m})$ and the difference between surface temperature and boiling temperature $\left({ }^{\circ} \mathrm{C}\right)$, respectively.

(ii) Solute may be deposited with the evaporation. Huang and Carey [16] indicates that the salt particles can puncture the vapor film and promote heat transfer if those precipitates are left on the surface during initial liquid-solid contact. Fig. 12 shows different alloy surfaces after quenching at the 
concentration of solutions of $0.4 \mathrm{M}$. It can be seen that there exists many more precipitates for solution of $\mathrm{Na}_{2} \mathrm{SO}_{4}$ due to the lowest solubility in the four dissolved salts. Minor precipitates are found for solution of $\mathrm{CaCl}_{2}$. And precipitates are hardly observed for solutions of $\mathrm{NaCl}$ and $\mathrm{MgSO}_{4}$.

(iii) The inhibition of bubble coalescence and reducing of vapor pressure will occur with the increased concentration.

The enhancement factor during transition boiling is shown in Fig. 11b. For all the solutions concentrations varying from $0 \mathrm{M}$ to $0.4 \mathrm{M}$, suppression is the largest for $\mathrm{NaCl}$ solution, somewhat less for $\mathrm{CaCl}_{2}$, and there has an improvement for $\mathrm{MgSO}_{4}$ solution. The reason is that $\mathrm{NaCl}$ solution exists larger descending of vapor pressure and the minimum surface tension (see Table 4 and Fig. 10). Therefore, the thickness of film decreases slightly. For $\mathrm{CaCl}_{2}$ solution, it has the largest descending of vapor pressure and the maximum surface gradient in the four salts. And the largest suppression of bubble coalescence and decrease of vapor film occur at the concentration of $0.2 \mathrm{M}$. Comparing with the most particles on the surface of $\mathrm{Na}_{2} \mathrm{SO}_{4}$, it can be speculated that the deposited particles have little effect on heat transfer. $\mathrm{MgSO}_{4}$ solution, which has the minimal change of vapor pressure and a stronger inhibition of bubble coalescence, promotes the heat transfer in transition boiling. And the enhancement increases with the increased salt concentration.
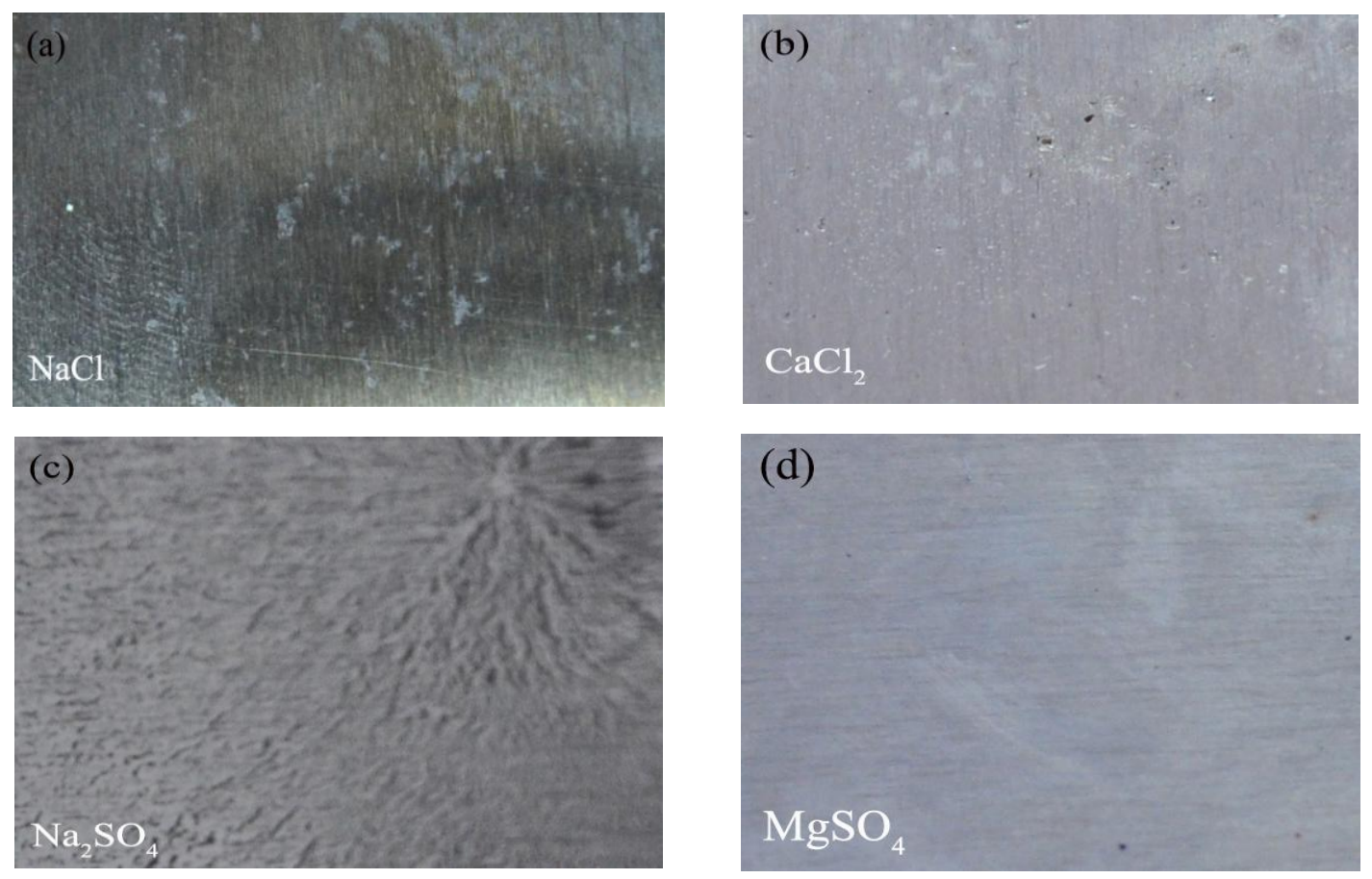

Fig. 12. Photos of different surfaces when dissolved salt of (a) $\mathrm{NaCl}$; (b) $\mathrm{CaCl}_{2}$; (c) $\mathrm{Na}_{2} \mathrm{SO}_{4}$ and (d) $\mathrm{MgSO}_{4}$ is used $(0.4 \mathrm{M})$.

The influence of dissolved salts on both nucleate and transition boiling leads to the variation of CHF temperature, as shown in Fig. 13. 


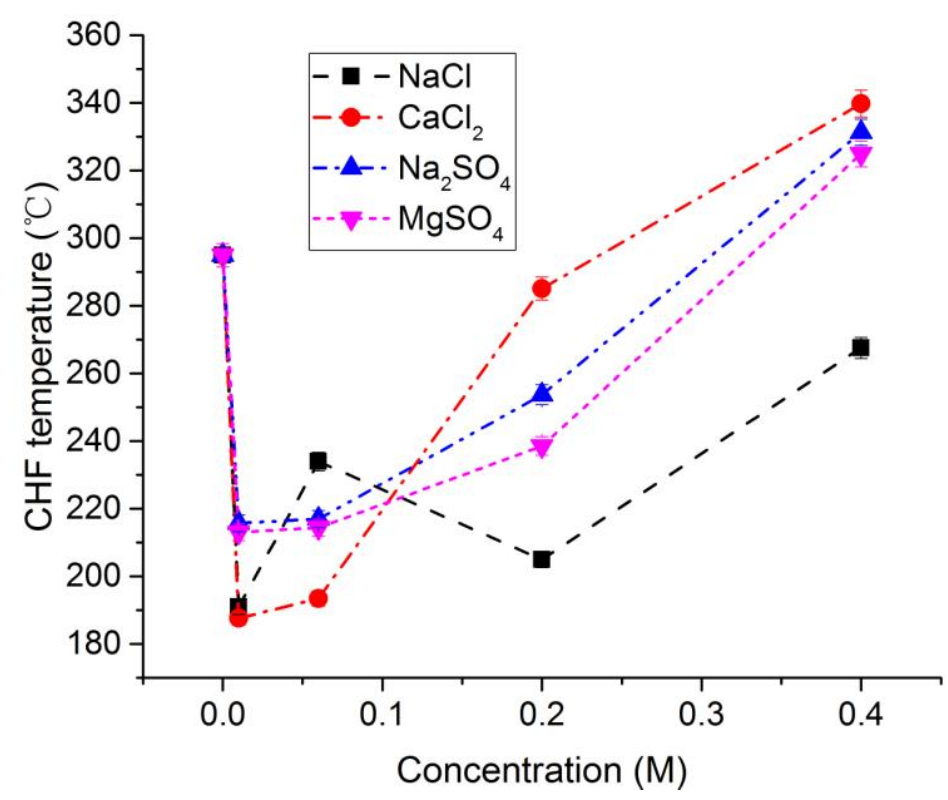

Fig. 13. The influence of salt concentration on CHF temperature.

CHF temperature decreases by approximately $100^{\circ} \mathrm{C}$ when the concentration of $\mathrm{NaCl}$ increases from $0 \mathrm{M}$ to $0.01 \mathrm{M}$. And then $\mathrm{CHF}$ temperature increases to $240^{\circ} \mathrm{C}$ at the concentration of $0.06 \mathrm{M}$. With the concentration further increasing, it firstly declines to $205^{\circ} \mathrm{C}$ (at the concentration of $0.2 \mathrm{M}$ ) and then increases to $260^{\circ} \mathrm{C}$ (at the concentration of $0.4 \mathrm{M}$ ). CHF temperature of $\mathrm{CaCl}_{2}$ solution also drops to $190^{\circ} \mathrm{C}$ at the concentration of $0.01 \mathrm{M}$. Beyond this concentration, CHF temperature increases with the concentration of $\mathrm{CaCl}_{2}$. Similar trend of $\mathrm{CHF}$ temperature is found for solutions of $\mathrm{Na}_{2} \mathrm{SO}_{4}$ and $\mathrm{MgSO}_{4}$ (see Fig. 13). Both these salts reduce to approximately $220^{\circ} \mathrm{C}$ at the concentration of 0.01 M. CHF temperature continues to increase with the concentration changing from $0.01 \mathrm{M}$ to $0.4 \mathrm{M}$.

It is worth noting that the variation trends of CHF temperature for the four solutions in this work are different with the results found by Cui et al. [15] and Abdalrahman at al. [17], which indicate that CHF temperature increases with the salt concentration ranging from $0 \mathrm{M}$ to $0.01 \mathrm{M}$. The reason may be attributed to the high volumetric flux used in this work (approximately $23 \mathrm{~kg} /\left(\mathrm{m}^{2} \mathrm{~s}\right)$ compared with $3 \mathrm{~kg} /\left(\mathrm{m}^{2} s\right)$ in references). At this high volumetric flux, there are hardly any particles for $0.01 \mathrm{M}$ solutions. Therefore, the only influence of dissolved salts is to change the chemical properties of liquid. However, future investigation would also be needed to verify the phenomenon.

\subsection{Effect of dissolved salts on CHF}

Fig. 14 shows the variation of CHF with concentration of four solutions. The results reveal that the change tendencies of CHF are diverse in each solution. When the $\mathrm{NaCl}$ solution is used, the CHF decreases from $2.5 \mathrm{MW} / \mathrm{m}^{2}$ (at the concentration of $0 \mathrm{M}$ ) to $2 \mathrm{MW} / \mathrm{m}^{2}$ (at the concentration of $0.01 \mathrm{M}$ ). Further increase of concentration results in the increasing of CHF. And the extent of increase is relatively small when the concentration varies from $0.06 \mathrm{M}$ to $0.4 \mathrm{M}$. With increasing concentration of $\mathrm{CaCl}_{2}$ solution, CHF diminishes to $2 \mathrm{MW} / \mathrm{m}^{2}$ (at $0.06 \mathrm{M}$ ) and then jumps to $5.5 \mathrm{MW} / \mathrm{m}^{2}$ (at $0.2 \mathrm{M}$ ). Further raising the concentration to $0.4 \mathrm{M}$ reduces $\mathrm{CHF}$ to $2.6 \mathrm{MW} / \mathrm{m}^{2}$. For $\mathrm{Na}_{2} \mathrm{SO}_{4}$ solution, CHF increases with the concentration, until the concentration exceeds $0.06 \mathrm{M}$. Then it drops to $2 \mathrm{MW} / \mathrm{m}^{2}$ at the concentration of $0.2 \mathrm{M}$ and increases $\mathrm{CHF}$ slightly $\left(2.03 \mathrm{MW} / \mathrm{m}^{2}\right)$ with further raising the 
concentration to $0.4 \mathrm{M}$. For dissolved salt of $\mathrm{MgSO}_{4}$, CHF increases from $2.5 \mathrm{MW} / \mathrm{m}^{2}$ (at the concentration of $0 \mathrm{M}$ ) to $3.9 \mathrm{MW} / \mathrm{m}^{2}$ (at the concentration of $0.2 \mathrm{M}$ ) and it drops to $3.5 \mathrm{MW} / \mathrm{m}^{2}$ at the concentration of $0.4 \mathrm{M}$. The variation trend of $\mathrm{CHF}$ for $\mathrm{MgSO}_{4}$ solution is similar to the finding observed by Cui et al. [15]. They find that CHF increases with salt concentration when the concentration changes within a certain range. Further increasing concentration will lead to CHF decreased.

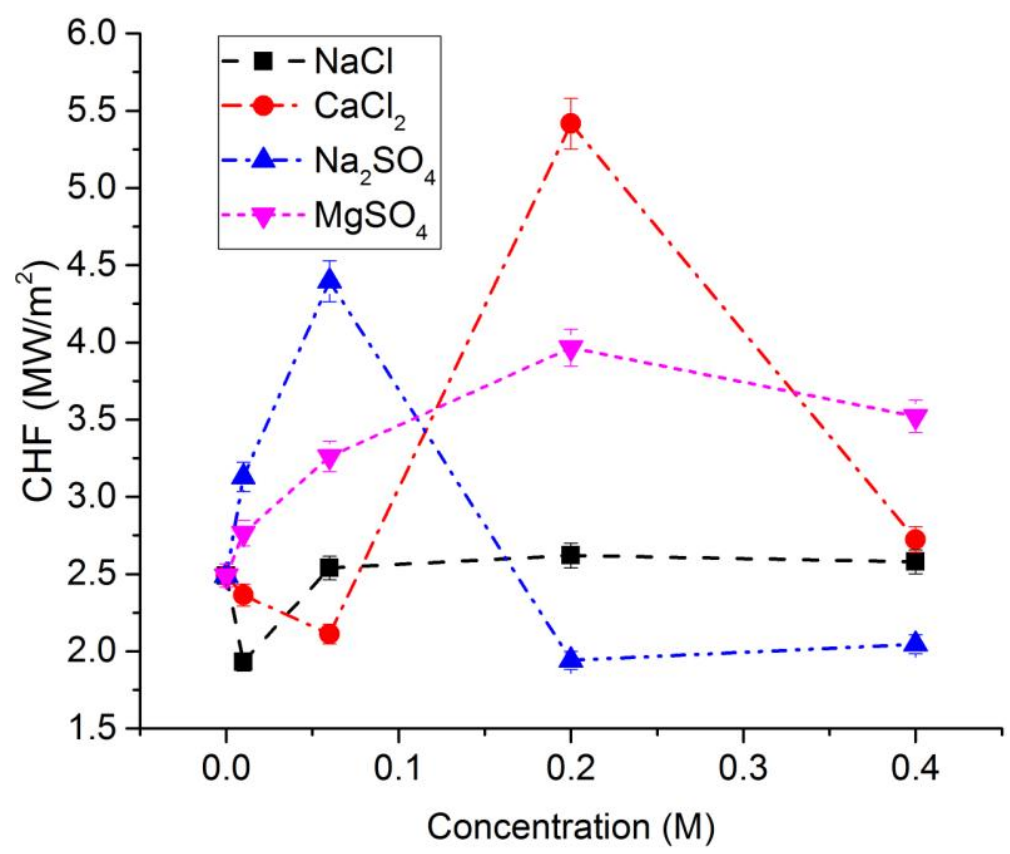

Fig. 14. The effect of salt concentration on CHF value.

It can be seen from Fig. 14 that, when concentration changes from $0 \mathrm{M}$ to $0.01 \mathrm{M}$, the CHF increases with salt concentration for $\mathrm{MgSO}_{4}$ and $\mathrm{Na}_{2} \mathrm{SO}_{4}$ solutions and decreases with salt concentration for dissolved salts of $\mathrm{NaCl}$ and $\mathrm{CaCl}_{2}$. Near CHF point, there have many more bubbles than any regimes during heat transfer and bubbles are particularly vulnerable to merge. Intermittent vapor blankets also begin to form. As is discussed in Section 3.2, the increasing concentration alters some physical properties of solutions which are inconsistent for different salts. For a solution of $\mathrm{NaCl}$, the transition concentration is $0.175 \mathrm{M}$. At the concentration of $0.01 \mathrm{M}$, no bubble coalescence is inhibited, and the thickness of vapor films does not decrease. However, vapor pressure is declined. Therefore, $\mathrm{CHF}$ of $\mathrm{NaCl}$ solution decreases to a lower value. Further increasing concentration leads to $\mathrm{CHF}$ improved and this enhancement is small due to the minimum surface tension gradient. A solution of $\mathrm{CaCl}_{2}$ has a transition concentration of $0.055 \mathrm{M}$ and surface tension gradient of 4.02 (see Table 4). So $\mathrm{CHF}$ of $\mathrm{CaCl}_{2}$ solution decreases with concentration varying from $0 \mathrm{M}$ to $0.06 \mathrm{M}$. At the concentration of $0.2 \mathrm{M}$, CHF of $\mathrm{CaCl}_{2}$ solution jumps to a very high value for the maximum surface tension gradient. $\mathrm{CaCl}_{2}$ solution also has the largest decreasing of vapor pressure, which causes $\mathrm{CHF}$ such a sharp drop from the concentration of $0.2 \mathrm{M}$ to $0.4 \mathrm{M}$. When the concentration of $\mathrm{Na}_{2} \mathrm{SO}_{4}$ solution changes from $0 \mathrm{M}$ to $0.4 \mathrm{M}$, CHF increases until the concentration exceeds $0.06 \mathrm{M}$. Further increasing concentration decreases $\mathrm{CHF}$ since $\mathrm{Na}_{2} \mathrm{SO}_{4}$ solution has larger declining of vapor pressure in the four salts. CHF of $\mathrm{MgSO}_{4}$ solution increases with concentration because of the minimum transition concentration $(0.032 \mathrm{M})$ and the lowest decreasing vapor pressure in the four salts.

However, there is still much work to understand mechanism of CHF since many parameters are changed with salt solution, e.g. specific heat of liquid, liquid and vapor density and saturation 
temperature.

\section{Conclusions}

A spray quenching experiment for investigating the influence of dissolved salts on heat transfer has been established. Four different solutions $\left(\mathrm{NaCl}, \mathrm{CaCl}_{2}, \mathrm{Na}_{2} \mathrm{SO}_{4}\right.$ and $\left.\mathrm{MgSO}_{4}\right)$ are tested and repeatability of measurement is verified. The heat fluxes are determined by IHCP. Temperature data measured by thermocouple are also smoothed by B-spline approximation with a smoothing parameter of $10^{-4}$. Several important discoveries are listed as follows:

1. For the four dissolved salts used in present work, heat transfer consists of three regimes, including transition boiling regime, nucleate boiling regime and single convective cooling regime. No film boiling regime is observed due to high volumetric flux and low water temperature.

2. There exist different phenomena for the salts at nucleate boiling. $\mathrm{MgSO}_{4}$ solution increases nucleate boiling heat transfer and $\mathrm{NaCl}$ has little improvement. $\mathrm{CaCl}_{2}$ solution causes the greatest influence, $\mathrm{Na}_{2} \mathrm{SO}_{4}$ somewhat less. The largest increase of heat transfer is found at concentration of $0.2 \mathrm{M}$ for solutions of $\mathrm{NaCl}, \mathrm{CaCl}_{2}$ and $\mathrm{MgSO}_{4}$, in contrast to the concentration of $0.06 \mathrm{M}$ for $\mathrm{Na}_{2} \mathrm{SO}_{4}$ solution. Effects of dissolved salts on nucleate boiling are attributed to surface tension gradient, transition concentration and vapor pressure.

3. During transition boiling regime, $\mathrm{MgSO}_{4}$ solution increases heat flux opposite to the reduction of heat flux for $\mathrm{NaCl}$ at all concentrations. Enhancement of heat flux is found at the concentration of $0.2 \mathrm{M}$ for $\mathrm{CaCl}_{2}$ and $0.06 \mathrm{M}$ for $\mathrm{Na}_{2} \mathrm{SO}_{4}$. The results display that deposited particles have little influence on heat transfer.

4. Comparing with the $\mathrm{CHF}$ of $\mathrm{DI}$ water, solution of $\mathrm{NaCl}$ has a reduction in contrast to an increase for $\mathrm{MgSO}_{4}$ solution at all concentrations. Solutions of $\mathrm{CaCl}_{2}$ and $\mathrm{Na}_{2} \mathrm{SO}_{4}$ exist enhancement at particular concentrations, which are $0.2 \mathrm{M}, 0.4 \mathrm{M}$ for $\mathrm{CaCl}_{2}$ solution and $0.01 \mathrm{M}, 0.06 \mathrm{M}$ for $\mathrm{Na}_{2} \mathrm{SO}_{4}$ solution.

\section{Acknowledgements}

The authors wish to thank Chuanmei Xie from Xi'an Suny Fine Chemical Co., Ltd for helpful discussions. This work is supported by National Science Foundation of China (Grant No. 51075332).

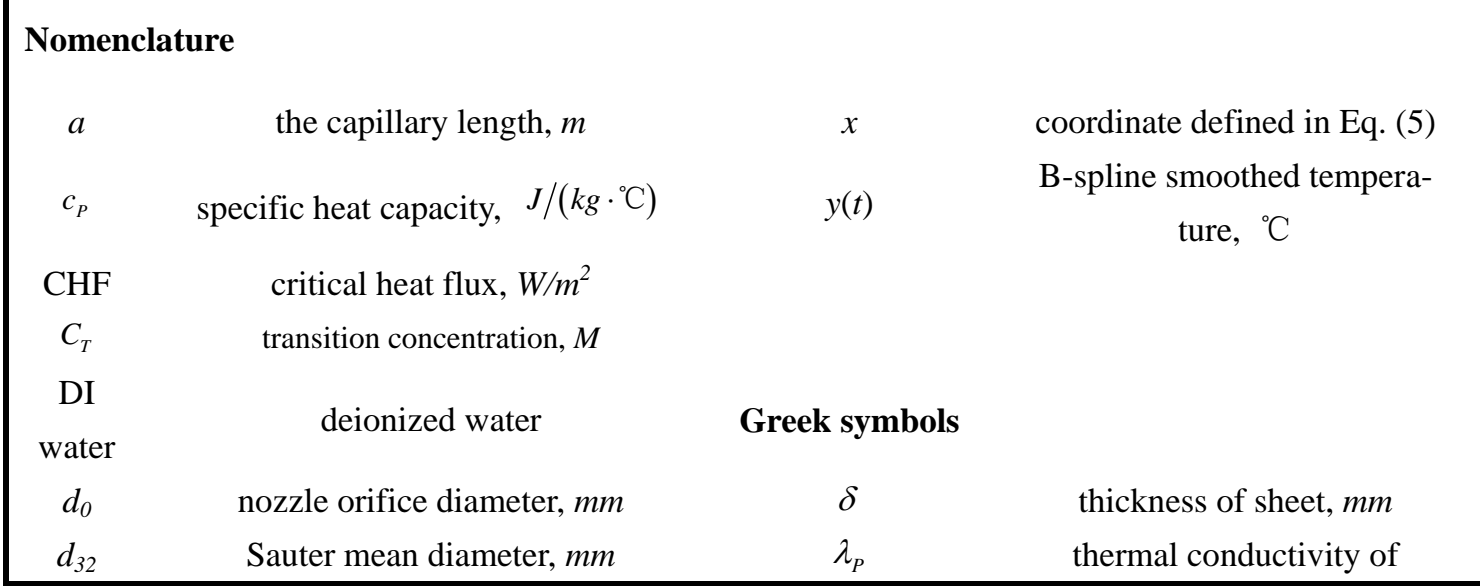




\begin{tabular}{|c|c|c|c|}
\hline$d \sigma / d c$ & surface tension gradient & $\lambda_{g}$ & $\begin{array}{l}\text { sheet, } W /\left(m \cdot{ }^{\circ} \mathrm{C}\right) \\
\text { thermal conductivity of va- } \\
\operatorname{por}, W /\left(m \cdot{ }^{\circ} \mathrm{C}\right)\end{array}$ \\
\hline$D_{b}$ & bubble departure diameter, $\mathrm{mm}$ & $\mu_{f}$ & water viscosity, $N \cdot s / m^{2}$ \\
\hline$D_{N}$ & nozzle distance, $\mathrm{mm}$ & $\mu_{g}$ & vapor viscosity, $N \cdot s / m^{2}$ \\
\hline$e$ & thickness of vapor film, $\mathrm{mm}$ & $\theta$ & spray angle, degree \\
\hline$h$ & heat transfer coefficient, $W /\left(m^{2} \cdot{ }^{\circ} \mathrm{C}\right)$ & $\rho_{g}$ & vapor density, $\mathrm{kg} / \mathrm{m}^{3}$ \\
\hline$h_{f g}$ & latent heat of evaporation, $\mathrm{J} / \mathrm{kg}$ & $\rho_{l}$ & fluid density, $\mathrm{kg} / \mathrm{m}^{3}$ \\
\hline$g$ & gravitational acceleration, $\mathrm{m} / \mathrm{s}^{2}$ & $\rho_{P}$ & aluminum density, $\mathrm{kg} / \mathrm{m}^{3}$ \\
\hline$m$ & $\begin{array}{l}\text { an integer which defines the length of } \\
\text { interval }\end{array}$ & $\sigma$ & surface tension, $\mathrm{N} / \mathrm{m}$ \\
\hline $\mathbf{U}$ & matrix of coefficient & $\tau_{i}$ & $\begin{array}{l}\text { time fraction of discrete temper- } \\
\text { ature data, } s\end{array}$ \\
\hline$n$ & $\begin{array}{l}\text { an integer which defines the number } \\
\text { of time-temperature data }\end{array}$ & $\psi$ & control point vector \\
\hline$P_{N}$ & nozzle pressure, $k P a$ & $\zeta$ & smoothing parameter \\
\hline$q$ & heat flux, $W / m^{2}$ & & \\
\hline$Q$ & flow rate, $L / \min$ & & \\
\hline$Q^{\prime \prime}$ & volumetric flux, $m^{3} /\left(m^{2} s\right)$ & & \\
\hline$t$ & time, $s$ & & \\
\hline$T$ & temperature,${ }^{\circ} \mathrm{C}$ & & \\
\hline $\mathbf{T}$ & temperature vector & & \\
\hline$T_{s}$ & surface temperature of specimens, ${ }^{\circ} \mathrm{C}$ & & \\
\hline$T_{w}$ & water temperature, ${ }^{\circ} \mathrm{C}$ & & \\
\hline
\end{tabular}

\section{References}

[1] J.T. Maximov, G.V. Duncheva, A.P. Anchev, M.D. Ichkova, Modeling of strain hardening and creep behavior of 2024-T3 aluminum alloy at room and high temperatures, Computational Materials Science 83 (2014) 381-393.

[2] A. Buczek, T. Telejko, Investigation of heat transfer coefficient during quenching in various cooling agents, International Journal of Heat and Fluid Flow 44 (2013) 358-364.

[3] Z.H. Liu, J. Wang, Study on film boiling heat transfer for water jet impinging on high temperature flat plate, International Journal of Heat and Mass Transfer 44(13) (2001) 2475-2481.

[4] D.D. Hall, I. Mudawar, Experimental and numerical study of quenching complex-shaped metallic alloys with multiple overlapping sprays, International Journal of Heat and Mass Transfer 38(7) (1995) 1201-1216. 
[5] D.D. Hall, I. Mudawar, Predicting the impact of quenching on mechanical properties of complex-shaped aluminum alloy parts, Journal of Heat Transfer 117(2) (1995) 479-488.

[6] N. Mascarenhas, I. Mudawar, Analytical and computational methodology for modeling spray quenching of solid alloy cylinders, International Journal of Heat and Mass Transfer 53(25) (2010) 5871-5883.

[7] I. Mudawar, W.S. Valentine, Determination of the local quench curve for spray-cooled metallic surfaces, Journal of Heat Treating 7(2) (1989) 107-121.

[8] I. Mudawar, T.A. Deiters, A universal approach to predicting temperature response of metallic parts to spray quenching, International Journal of Heat and Mass Transfer 37(3) (1994) 347-362.

[9] H.M. Al-Ahmadi, S.C. Yao, Spray cooling of high temperature metals using high mass flux industrial nozzles, Experimental Heat Transfer 21(1) (2008) 38-54.

[10] J.R. Rybicki, I. Mudawar, Single-phase and two-phase cooling characteristics of upward-facing and downward-facing sprays, International Journal of Heat and Mass Transfer 49(1-2) (2006) $5-16$.

[11] J. Wendelstorf, K.H. Spitzer, R. Wendelstorf, Spray water cooling heat transfer at high temperatures and liquid mass fluxes, International Journal of Heat and Mass Transfer 51(19-20) (2008) 4902-4910.

[12] R.H. Chen, L.C. Chow, J.E. Navedo, Effects of spray characteristics on critical heat flux in sub-cooled water spray cooling, International Journal of Heat and Mass Transfer 45(19) (2002) 4033-4043.

[13] Q. Cui, S. Chandra, S. McCahan, The effect of dissolving gases or solids in water droplets boiling on a hot surface, Journal of Heat Transfer 123(4) (2001) 719-728.

[14] Q. Cui, S. Chandra, S. McCahan, The effect of dissolving salts in water sprays used for quenching a hot surface: Part 1- Boiling of Single Droplets, Journal of Heat Transfer 125(2) (2003) 326-332.

[15] Q. Cui, S. Chandra, S. McCahan, The effect of dissolving salts in water sprays used for quenching a hot surface: Part 2 - Spray Cooling, Journal of Heat Transfer 125(2) (2003) 333-338.

[16] C.K. Huang, V.P. Carey, The effects of dissolved salt on the Leidenfrost transition, International Journal of Heat and Mass Transfer 50(1) (2007) 269-282.

[17] K.H.M. Abdalrahman, Sabariman, E. Specht, Influence of salt mixture on the heat transfer during spray cooling of hot metals, International Journal of Heat and Mass Transfer 78 (2014) 76-83.

[18] U. Alam, Experimental study of local heat transfer during quenching of metals by spray and multiple jets (Ph.D. thesis), Otto-von-Guericke University Magdeburg 2011.

[19] V.S.J. Craig, B.W. Ninham, R.M. Pashley, Effect of electrolytes on bubble coalescence, Nature 364(6435) (1993) 317-319.

[20] R.C. Guo, J.J. Wu, W.P. Liu, Z.K. Zhang, M.Z. Wang, S.C. Guo, Investigation of heat transfer on 2024 aluminum alloy thin sheets by water spray quenching, Experimental Thermal and Fluid Science 72 (2016) 249-257.

[21] N. Zhao, Y.Q. Yang, M. Han, X. Luo, G.H. Feng, R.J. Zhang, Finite element analysis of pressure on 2024 aluminum alloy created during restricting expansion deformation heat treatment, Transactions of Nonferrous Metals Society of China 22(9) (2012) 2226-2232.

[22] R.J. Moffat, Describing the uncertainties in experimental results, Experimental Thermal and Fluid Science 1 (1988) 3-17.

[23] K.A. Estes, I. Mudawar, Correlation of Sauter mean diameter and critical heat flux for spray cooling of small surfaces, International Journal of Heat and Mass Transfer 38(16) (1995) 2985-2996. 
[24] P.E. Liley, Steam Tables in SI Units, private communication, School of Mechanical Engineering, Purdue University, West Lafayette, IN (1984) C862.

[25] I. Mudawar, K.A. Estes, Optimizing and predicting CHF in spray cooling of a square surface, Journal of heat transfer 118(3) (1996) 672-679.

[26] O.R. Burggraf, An exact solution of the inverse problem in heat conduction theory and applications, Journal of Heat Transfer 86(3) (1964) 373-382

[27] W.J.J. Vorster, S.A. Schwindt, J. Schupp, A.M. Korsunsky, Analysis of spray field development on a vertical surface during water spray-quenching using a flat spray nozzle, Applied Thermal Engineering 29 (7) (2009) 1406-1416.

[28] R.C. Guo, J.J. Wu, H. Fan, X.P. Zhan, The effects of spray characteristic on heat transfer dur-ing spray quenching of aluminum alloy 2024, Experimental Thermal and Fluid Science 76 (2016) 211-220.

[29] C.H. Reinsch, Smoothing by spline functions I, Numerische Mathematik 10(3) (1967) 177-183.

[30] J. Taler, Theory of transient experimental techniques for surface heat transfer, International Journal of Heat and Mass Transfer 39(17) (1996) 3733-3748.

[31] W.P. Klinzing, J.C. Rozzi, I. Mudawar, Film and transition boiling correlations for quenching of hot surfaces with water sprays, Journal of Heat Treating 9 (1992) 91-103.

[32] C. Browne, R.F. Tabor, D.Y.C. Chan, R.R. Dagastine, M. Ashokkumar, F. Grieser, Bubble coalescence during acoustic cavitation in aqueous electrolyte solutions, Langmuir 27(19) (2011) 12025-12032.

[33] P.K. Weissenborn, R.J. Pugh, Surface tension of aqueous solutions of electrolytes: relationship with ion hydration, oxygen solubility, and bubble coalescence, Journal of Colloid and Interface Science 184(2) (1996) 550-563.

[34] L.A. Cisternas, E.J. Lam, An analytic correlation for the vapor pressure of aqueous and non-aqueous solutions of single and mixed electrolytes. Part II . Application and extension, Fluid Phase Equilibria 62(1-2) (1991) 11-27.

[35] A.L. Biance, C. Clanet, D. Quere. Leidenfrost drops, Physics of Fluids 15(6) (2003) 1632-1637. 


\section{Figure Captions}

Fig. 1. Schematic diagram of (a) apparatus for spray quenching and (b) nozzles and thermocouple locations (unit: $\mathrm{mm}$ ).

Fig. 2. Schematic diagram of two nozzles' symmetry.

Fig. 3. Schematic diagram of volumetric flux distribution (Mudawar and Estes [25]).

Fig. 4. The discrete data and smoothed curves obtained by B-spline approximation with different smoothing parameters.

Fig. 5. A typical quenching profile repeated three times using deionized water.

Fig. 6. Example of measured spray quenching curves when the $\mathrm{MgSO}_{4}$ is used as solute.

Fig. 7. The calculated heat flux during spray quenching when the DI water is used.

Fig. 8. The effect of dissolved salt on heat flux for aluminum 2024: (a) $\mathrm{NaCl}$; (b) $\mathrm{CaCl}_{2}$; (c) $\mathrm{Na}_{2} \mathrm{SO}_{4}$ and (d) $\mathrm{MgSO}_{4}$.

Fig. 9. Schematic inhibition mechanism of bubble coalescence [32].

Fig. 10. Variations of vapor pressure with concentration at $373 \mathrm{~K}$.

Fig. 11. The effect of salts concentration on heat transfer in (a) nucleate boiling and (b) transition boiling.

Fig. 12. Photos of different surfaces when dissolved salt of (a) $\mathrm{NaCl}$; (b) $\mathrm{CaCl}_{2}$; (c) $\mathrm{Na}_{2} \mathrm{SO}_{4}$ and (d) $\mathrm{MgSO}_{4}$ is used $(0.4 \mathrm{M})$.

Fig. 13. The influence of salt concentration on CHF temperature.

Fig. 14. The effect of salt concentration on CHF value. 